\title{
The airborne mass spectrometer AIMS - Part 2: Measurements of trace gases with stratospheric or tropospheric origin in the UTLS
}

\author{
Tina Jurkat $^{1}$, Stefan Kaufmann ${ }^{1}$, Christiane Voigt ${ }^{1,2}$, Dominik Schäuble ${ }^{1, a}$, Philipp Jeßberger ${ }^{1, b}$, and Helmut Ziereis ${ }^{1}$ \\ ${ }^{1}$ Deutsches Zentrum für Luft- und Raumfahrt, Institut für Physik der Atmosphäre, Oberpfaffenhofen, Germany \\ ${ }^{2}$ Johannes Gutenberg-Universität, Institut für Physik der Atmosphäre, Mainz, Germany \\ a now at: Institute for Advanced Sustainability Studies, Potsdam, Germany \\ ${ }^{b}$ now at: Bayerische Patentallianz, Munich, Germany \\ Correspondence to: Tina Jurkat (tina.jurkat@dlr.de)
}

Received: 2 December 2015 - Published in Atmos. Meas. Tech. Discuss.: 21 December 2015

Revised: 22 March 2016 - Accepted: 4 April 2016 - Published: 29 April 2016

\begin{abstract}
Understanding the role of climate-sensitive trace gas variabilities in the upper troposphere and lower stratosphere region (UTLS) and their impact on its radiative budget requires accurate measurements. The composition of the UTLS is governed by transport and chemistry of stratospheric and tropospheric constituents, such as chlorine, nitrogen oxide and sulfur compounds. The Atmospheric chemical Ionization Mass Spectrometer AIMS has been developed to accurately measure a set of these constituents on aircraft by means of chemical ionization. Here we present a setup using $\mathrm{SF}_{5}^{-}$reagent ions for the simultaneous measurement of trace gas concentrations of $\mathrm{HCl}, \mathrm{HNO}_{3}$ and $\mathrm{SO}_{2}$ in the pptv to ppmv $\left(10^{-12}\right.$ to $\left.10^{-6} \mathrm{~mol} \mathrm{~mol}^{-1}\right)$ range with in-flight and online calibration called AIMS-TG (Atmospheric chemical Ionization Mass Spectrometer for measurements of trace gases). Part 1 of this paper (Kaufmann et al., 2016) reports on the UTLS water vapor measurements with the AIMS-H2O configuration. The instrument can be flexibly switched between two configurations depending on the scientific objective of the mission. For AIMS-TG, a custom-made gas discharge ion source has been developed for generation of reagent ions that selectively react with $\mathrm{HCl}$, $\mathrm{HNO}_{3}, \mathrm{SO}_{2}$ and $\mathrm{HONO} . \mathrm{HNO}_{3}$ and $\mathrm{HCl}$ are routinely calibrated in-flight using permeation devices; $\mathrm{SO}_{2}$ is continuously calibrated during flight adding an isotopically labeled ${ }^{34} \mathrm{SO}_{2}$ standard. In addition, we report on trace gas measurements of HONO, which is sensitive to the reaction with $\mathrm{SF}_{5}^{-}$. The detection limit for the various trace gases is in the low 10 pptv range at a $1 \mathrm{~s}$ time resolution with an overall uncertainty of the measurement of the order of $20 \%$. AIMS has
\end{abstract}

been integrated and successfully operated on the DLR research aircraft Falcon and HALO (High Altitude LOng range research aircraft). As an example, measurements conducted during the TACTS/ESMVal (Transport and Composition of the LMS/UT and Earth System Model Validation) mission with HALO in 2012 are presented, focusing on a classification of tropospheric and stratospheric influences in the UTLS region. The combination of AIMS measurements with other measurement techniques yields a comprehensive picture of the sulfur, chlorine and reactive nitrogen oxide budget in the UTLS. The different trace gases measured with AIMS exhibit the potential to gain a better understanding of the trace gas origin and variability at and near the tropopause.

\section{Introduction}

Trace gas measurements at low concentrations with high spatial resolution are challenging. Particularly in the extratropical upper troposphere and lower stratosphere, a sensitive region concerning the Earth's radiation budget due to its low temperatures and strong trace gas gradients, accurate measurements are needed (Hegglin et al., 2010). Exchange of stratospheric and tropospheric air masses are often analyzed by means of tracer-tracer correlations, which help to identify transport processes, chemical processing and microphysical interaction (Hoor et al., 2004; Pan et al., 2004). While in some studies one unambiguous tracer serves as a marker of a specific source region like e.g., $\mathrm{C}_{2} \mathrm{Cl}_{4}$ (Ashfold et al., 2015), other processes can only be explained with a combination of 
trace gases (Ungermann et al., 2013). Particularly changes of ozone and water vapor near the tropopause have a large impact on the radiation budget (Riese et al., 2012). Bidirectional exchange occurs where isentropes cross the extratropical tropopause, affecting the ozone concentration at the tropopause in various ways (Holton et al., 1995). Chemistryclimate models, however, struggle to reproduce the seasonal variability particularly at $200 \mathrm{hPa}$ (Hegglin et al., 2010). Photochemical processing, convection and downward transport change ozone and nitric acid concentrations in the upper troposphere, thereby affecting the radiative budget of the free troposphere and upper troposphere and lower stratosphere region (UTLS) (Lacis et al., 1990). In contrast to spaceborne satellite measurements of the UTLS that often do not provide the high resolution and low detection limit needed to investigate trace gas transport and mixing (e.g Lary and Aulov, 2008), airborne in situ measurements exhibit a large potential to investigate these processes from small-scale turbulent mixing to mesoscale variability.

Chemical ionization mass spectrometry (CIMS) has been used for decades on aircraft (e.g., Reiner et al., 1998; Viggiano and Hunton, 1999), rockets (Schlager and Arnold, 1990) and balloons (Arnold and Spreng, 1994) for detection of low atmospheric trace gas concentration up to altitudes of $65 \mathrm{~km}$. The efficiency of ion-molecule reactions combined with a fast ion analyzer like a linear quadrupole mass spectrometer has been exploited for measurements of different trace gas constituents and atmospheric processes (Arnold et al., 1992; Berresheim et al., 2002; Zondlo et al., 2003; Nowak et al., 2007; Veres et al., 2008). However, the importance of the detection mechanism cannot be overestimated when uncertainties due to interferences and ambiguities in measurement systems remain. In addition, the time resolution and accuracy of CIMS can be sufficient to characterize atmospheric processes from an aircraft platform.

$\mathrm{HCl}$ (hydrogen chloride) and $\mathrm{ClONO}_{2}$ (chlorine nitrate) are the main components in the reactive chlorine budget in the stratosphere, and thus once activated, chlorine participates in catalytic ozone depletion cycles (Seinfeld and Pandis, 1998). Furthermore, $\mathrm{HCl}$ can be used in particular as an unambiguous tracer for downward transport of stratospheric air into the troposphere (Marcy et al., 2004). It is a powerful tool to quantify the contribution of stratospheric ozone in mixed air above and below the tropopause (Jurkat et al., 2014). Only few in situ measurements exist that detect $\mathrm{HCl}$ with low detection limits of less than $0.1 \mathrm{ppbv}$ (Arnold and Spreng, 1994; Marcy et al., 2005). In contrast, a number of CIMS techniques have been used in the past to detect sulfur dioxide $\left(\mathrm{SO}_{2}\right)$ (Hanke et al., 2003; Huey et al., 2004; Fiedler et al., 2009). Most of them made use of the $\mathrm{CO}_{3}^{-}$reagent ions due to a large reaction rate coefficient and little interfering products, resulting in low detection limits of $0.01 \mathrm{ppbv}$. These detection limits are necessary to characterize the generally low $\mathrm{SO}_{2}$ background in the stratosphere. Conversion to sulfuric acid leads to particle formation, which in turn in- teract with other trace gases, clouds and radiation. Airborne measurements of $\mathrm{SO}_{2}$ furthermore enable spatially confined air masses with the influence of anthropogenic pollution to be identified (e.g., Fiedler et al., 2009) as well as plumes of volcanic origin in the UTLS (Jurkat et al., 2010). Nitric acid $\left(\mathrm{HNO}_{3}\right)$ has been measured by various CIMS techniques (Schneider et al., 1998; Neuman et al., 2001; Huey et al., 2004; Le Breton et al., 2014) for it plays a major role in stratospheric chemistry (Crutzen and Arnold, 1986; Voigt et al., 2000). Contributions to the nitric acid budget in the upper troposphere are lightning (Schumann and Huntrieser, 2007), anthropogenic emissions like air traffic (Voigt et al., 2010) and biomass burning (Fiedler et al., 2011).

The Atmospheric chemical Ionization Mass Spectrometer for measurements of trace gases (AIMS-TG) described in this work makes use of chemical ionization with an electrical discharge source, generating $\mathrm{SF}_{5}^{-}$reagent ions. We report on simultaneous and independent measurements of $\mathrm{HCl}, \mathrm{HNO}_{3}$, $\mathrm{HONO}$ and $\mathrm{SO}_{2}$ with $\mathrm{SF}_{5}^{-}$reagent ions and discuss advantages and challenges of the technique. Measurements of other trace gases like $\mathrm{ClONO}_{2}$ and $\mathrm{HBr}$, sensitive to the reaction with $\mathrm{SF}_{5}^{-}$, will be discussed elsewhere. The method was originally established by Marcy et al. (2005) with focus on $\mathrm{HCl}$, $\mathrm{HNO}_{3}$ and $\mathrm{ClONO}_{2}$ measurements in the TTL and lower stratosphere. During the CONCERT2008 campaign (CONtrail and Cirrus ExpeRimenT) (Voigt et al., 2010), the detection mechanism using $\mathrm{SF}_{5}^{-}$reagent ions was extended to fast and precise measurements of $\mathrm{HONO}$ and $\mathrm{SO}_{2}$ in young aircraft exhaust plumes, in order to derive the conversion efficiency from fuel sulfur to sulfuric acid (Jurkat et al., 2011).

The AIMS-TG as well as the configuration AIMS-H2O were deployed on aircraft for the first time during the CONCERT2011 campaign on the Falcon (Voigt et al., 2014; Kaufmann et al., 2014) and were later adapted to HALO (High Altitude LOng range research aircraft) for TACTS/ESMVal (Transport and Composition of the LMS/UT and Earth System Model Validation) in 2012 (Jurkat et al., 2014) and for ML-CIRRUS (Mid-Latitude Cirrus) in 2014 (Kaufmann et al., 2016; Voigt et al., 2016). Part 1 of the AIMS paper describes the water vapor configuration AIMS-H2O (Kaufmann et al., 2016). Here, we present the chemical ionization and calibration methods, inlet specifications and sensitivity studies for the trace gas configuration, focusing on $\mathrm{HCl}$, $\mathrm{HNO}_{3}, \mathrm{HONO}$ and $\mathrm{SO}_{2}$.

\section{The setup of the mass spectrometer}

The setup of the ion detection unit of AIMS is a linear quadrupole mass spectrometer (Huey et al., 2007) that is described in detail in Part 1 (Kaufmann et al., 2016). Figure 1a shows a schematic of the main components of AIMS-TG which are specified in detail in the following sections. We describe the components of AIMS-TG of the HALO configuration, in particular the inlet line, the pressure regulation 


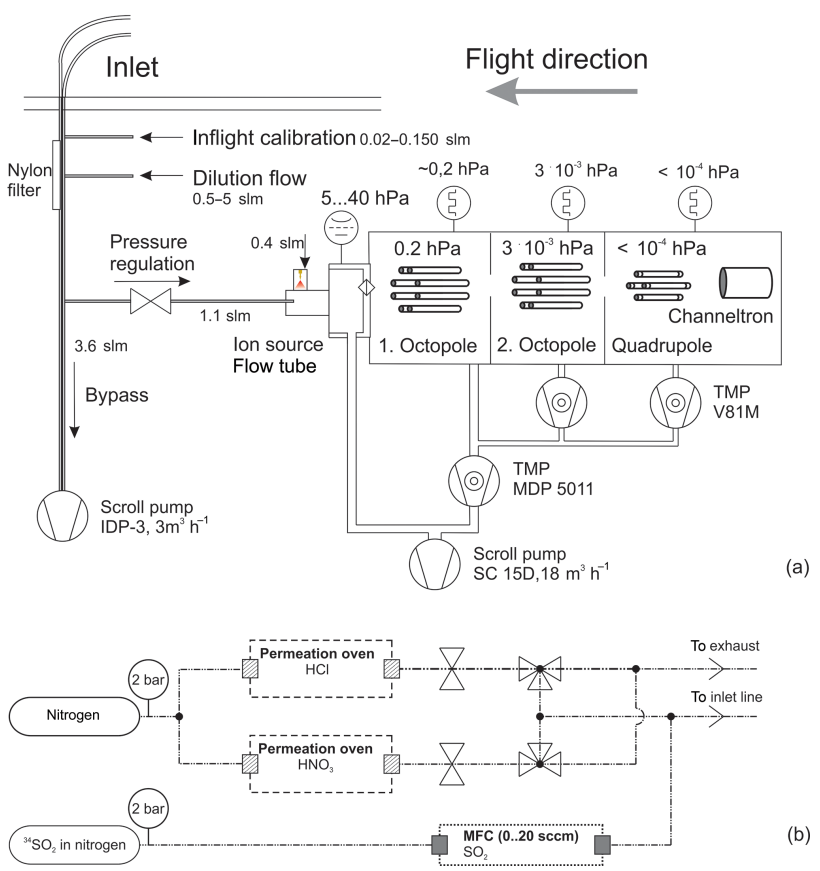

Figure 1. (a) Schematic of the flight configuration of AIMS-TG. Ambient air enters via two backward-facing inlets and passes a pressure regulation valve before entering the flow tube. One inlet line is equipped with a nylon filter for background measurements. The detailed setup of the ion source for the AIMS-TG measurement mode is depicted in Fig. 2. The ion beam of reagent and product ion is then focussed by two adjacent octopoles and finally separated by mass-to-charge ratio in the quadrupole. Connections for an optional dilution of ambient air and for addition of trace gases for in-flight calibration are mounted right beneath the inlet and are shown in detail in (b). Two permeation ovens with PFA and glass containers are used for $\mathrm{HCl}$ and $\mathrm{HNO}_{3}$ generation. Critical orifices regulate the flow that is either introduced in the upper inlet line or diverted to the exhaust. $\mathrm{SO}_{2}$ is taken from a stainless steel cylinder filled with generally $2.7 \mathrm{ppmv} \mathrm{SO}_{2}$ in $\mathrm{N}_{2}$.

valve, the electrical discharge source, the background measurements and the calibration components. Particular emphasis is placed on the calibration units of AIMS-TG, which are used in-flight and in post-flight calibration procedures. All components are designed to meet the specific requirements of the four trace gases to achieve the optimal precision, accuracy and time resolution.

\subsection{Inlet line}

The setup of the inlet line for the AIMS-TG configuration is adapted to the needs of the detection of reactive gases. Especially the acidic molecules $\mathrm{HNO}_{3}$ and $\mathrm{HCl}$ tend to stick on the walls of inlet tubes depending on atmospheric conditions, surface temperature and passivation (Neuman et al., 1999). In order to minimize this effect, we use $1 / 2^{\prime \prime}$ diameter PFA tubes with a large volume to surface ratio for the inlet and bypass line including the tubing inside the trace gas inlets (TGIs) of HALO and Falcon. Two backward-facing inlet lines are used: one for atmospheric sampling, one for extraction of scrubbed air with a nylon filter. Swagelok PFA connectors are used in limited numbers. In sensitive parts such as valves and orifices with small volume to surface ratios, we integrated smoothed or cast PFA inlays. Heating of the inlet and of the tubes inside the aircraft cabin is realized ana- logue to the AIMS-H2O configuration. In order to reduce the number of connectors and bends with rough surfaces, only one direct connection of the calibration line to the main inlet line is used instead of three for three different calibration gases. A continuous flow through the calibration lines is maintained by using a three-way valve with either connection to the inlet or diversion to the exhaust. Thus the passivation of the calibration tubes is constant and guarantees a faster supply of the calibration substance. From the inlet tip down to the ionization region, all wetted parts are PFA. The sampling flow of 1.1 standard $\mathrm{L} \mathrm{min}^{-1}$ into the mass spectrometer is regulated by the combination of a critical orifice in front of the scroll pump and a constant pressure downstream of the ionization region. Additionally a high bypass flow of 3.6 standard $\mathrm{L} \mathrm{min}^{-1}$ regulated by a mass flow controller (MFC; MKS Instruments, 30 standard $\mathrm{L} \mathrm{min}^{-1}$ ), generated by the additional scroll pump (IDP-3, $3.6 \mathrm{~m}^{3} \mathrm{~h}^{-1}$ ), is applied to minimize residence time in the sampling line (see also Kaufmann et al., 2016). In total, the inlet line length is between 1.2 and $2 \mathrm{~m}$, depending on the distance of the rack to the inlet aperture on the fuselage of the aircraft. Assuming a laminar flow, residence times are therefore less than a second, thus minimizing thermal destruction, heterogeneous 


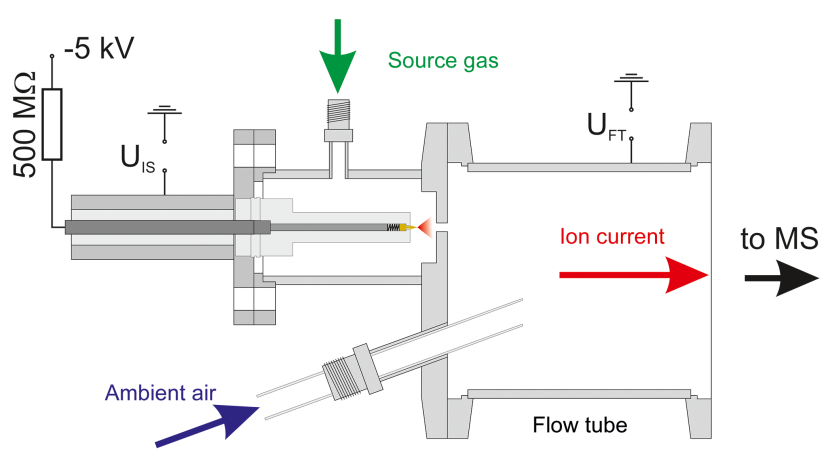

Figure 2. The gas discharge ion source for AIMS-TG: the electrical setup is identical to the AIMS- $\mathrm{H}_{2} \mathrm{O}$ source except for the high voltage potential which is negative and generally lower in absolute measures. In this assembly, the source gas $\mathrm{SCF}_{8}$ is ionized in the region between the needle tip and an aperture plate. Afterwards the source gas carrying the reagent ions is mixed with ambient air in the flow tube where trace gases react with $\mathrm{SF}_{5}^{-}$to form product ions. To enhance mixing between trace gases and reagent ions, the sample flow with ambient air is directed into the ion current.

reaction or loss due to uptake on the surface. Any loss would be accounted for by the in-flight calibration.

\subsection{Pressure regulation}

Constant flow and pressure conditions in the ion source, flow reactor and mass spectrometer, is guaranteed using an automatically controlled pressure regulation valve mounted upstream of the ion source (Fig. 1). Pressure regulation has to compensate for rapid ambient pressure changes between 150 and $1000 \mathrm{hPa}$, to account for turbulent conditions such as young aircraft plumes and rapid ascents and descents. It also has to be very accurate since the reaction rate for the ionmolecule reactions in the flow reactor scales linearly with the pressure and the partial pressure of the trace gas. For Falcon and HALO configurations, the main body of the valve consists of PFA (Swagelok PFA43S4) with an inlay of a cast PFA for AIMS-TG. The lever of the manual valve was removed and replaced by a custom-made adapter to control the valve by a servomotor (DA 22-30-4128, Volz Servos GmbH, Germany). The motor is controlled by a proportional-integralderivative controller, regulating the pressure measured by a Baratron ${ }^{\circledR}$ manometer (MKS Instruments, Type 727) downstream of the flow reactor. For a similar representative flight sequence, the $99 \%$ percentile of the pressure regulation for AIMS-TG is around $0.04 \mathrm{hPa}$ at a nominal pressure of $33 \mathrm{hPa}$. The slightly higher deviation for the PFA valve to the stainless steel valve is due to the roughness of the material of the valve body. This may explain why the valve reacts with a certain delay. However, the pressure regulation can compensate typical descent rates of about $600 \mathrm{~m} \mathrm{~min}^{-1}$ during regular flight manoeuvres, thus enabling a continuous measurement over a wide range of atmospheric pressures.

\subsection{Custom-made discharge ion source}

A schematic of the ion source for AIMS-TG is shown in Fig. 2. It has a different geometry compared to the AIMS$\mathrm{H} 2 \mathrm{O}$ ion source since the reaction mechanisms differ. The construction of the ion source is inspired by the work of Kürten et al. (2011). The general mechanism applied here is chemical ionization which is the selective reaction of ambient trace gases with an artificially produced reagent ion. In contrast to direct ionization of ambient air as employed by AIMS-H2O, artificial ions are produced by passing a constant flow of $20 \mathrm{sccm}$ source gas (1000 ppmv $\mathrm{SCF}_{8}$ in $\mathrm{N}_{2}$, Deuste-Steininger, Germany) mixed with a carrier gas of 0.4 standard $\mathrm{L} \mathrm{min}^{-1}$ nitrogen through the ionization region which is located between the needle tip and a $1.4 \mathrm{~mm}$ aperture. The flow was optimized to achieve highest reagent ion count rates. The needle has a negative potential of $-0.4 \mathrm{kV}$, so positive ions are attracted to the negative needle tip, and the major charge carriers in the drift region are negative ions and electrons. Higher potentials applied to the needle increased the reagent ion count rate only insignificantly but had a major effect on the background counts of some masses (Fig. S1 in the Supplement). The $\mathrm{SF}_{5}^{-}$reagent ions are generated by collision dissociation into $\mathrm{SF}_{5}$ and $\mathrm{CF}_{3}$ and subsequent electron attachment. A negative, repulsive potential (of about $-7.3 \mathrm{~V}$ ) is additionally applied to the wall of the ion source to avoid losses of ions by collision with the wall. The potential difference from flow tube to aperture plate additional guides the ion and increases the transmission. The pressure in the flow tube and the ion source is set to $33.3 \mathrm{hPa}$. After the ionized source gas with $\mathrm{SF}_{5}^{-}$passes the aperture, it is mixed with ambient air which is guided to the flow reactor (KF40 stainless steel) via a $1 / 4^{\prime \prime}$ PFA tube. Inside the reactor, chemical ionization takes place. The high dipole moment of the $\mathrm{SF}_{5}^{-}$ions produces a large reaction cross section with the trace gases in the ambient air, with a reaction time of about $100 \mathrm{~ms}$ and reaction constants of the order of several $10^{-9} \mathrm{~cm}^{3}$ molecules ${ }^{-1} \mathrm{~s}^{-} 1$. Both reagent and product ions, are quasi-simultaneously detected in the mass spectrometer. A significant difference to the direct ionization method applied for $\mathrm{H}_{2} \mathrm{O}$ measurements is the enhanced reaction time in the flow reactor constrained by the length of the reactor and the total gas flow. Additionally due to the low concentrations in the atmosphere, a higher pressure is needed to enhance the reaction rate and enable the gas discharge of the $\mathrm{SCF}_{8} / \mathrm{N}_{2}$ source gas. Earlier work (Marcy et al., 2005; Jurkat et al., 2010), applying the same reaction mechanism, used radioactive sources for ionization. The ionization by alpha particles from ${ }^{210} \mathrm{Po}$ is lower in energy; however continuous ionization taking place in the ion source at high pressures in the presence of $\mathrm{O}_{2}$ produces a significant amount of $\mathrm{HNO}_{3}$, which interferes with the measurements. The use of discharge ionization reduces this background significantly. However, on some masses, enhanced noise is observed due to artificially produced ions and radicals. This type of noise can generally 
be avoided by applying a low potential to the ion source or generating a more stable discharge region (Fig. S1).

\section{Ion molecule reactions}

Generation of the reagent ions occurs in the ion source which is directly connected to the flow tube. Reagent ions and trace gases enter the flow tube through two inlets with an angle of approximately $30^{\circ}$ where they are rapidly mixed. The net reaction path is the transfer of an $\mathrm{F}^{-}$ion from the reagent ion to the trace gas molecule to form a product ion:

$\mathrm{X}+\mathrm{SF}_{5}^{-} \rightarrow \mathrm{FX}^{-}+\mathrm{SF}_{4}$,

where $\mathrm{X}$ stands for reactive trace gas species. For acidic trace gases, the higher proton affinity of $\mathrm{F}^{-}$compared to $\mathrm{NO}_{3}^{-}$, $\mathrm{NO}_{2}^{-}$and $\mathrm{Cl}^{-}$leads to a donation of the $\mathrm{H}^{+}$ion to form $\mathrm{HF}$ molecules which couple to the reduced anion via hydrogen bonds. For the proton donating compounds, we obtain

$\mathrm{HNO}_{3}+\mathrm{SF}_{5}^{-} \rightarrow \mathrm{HFNO}_{3}^{-}+\mathrm{SF}_{4}$

$\mathrm{HCl}+\mathrm{SF}_{5}^{-} \rightarrow \mathrm{HFCl}^{-}+\mathrm{SF}_{4}$

$\mathrm{HONO}+\mathrm{SF}_{5}^{-} \rightarrow \mathrm{HFNO}_{2}^{-}+\mathrm{SF}_{4}$.

Rate constants for these reactions are quantified by laboratory studies to $k_{\mathrm{HNO}_{3}}=2.1 \times 10^{-9} \mathrm{~cm}^{3}$ molecules ${ }^{-1} \mathrm{~s}^{-1}$ and $k_{\mathrm{HCl}}=1.0 \times 10^{-9} \mathrm{~cm}^{3}$ molecule ${ }^{-1} \mathrm{~s}^{-1}$ (Lovejoy and Wilson, 1998; Marcy et al., 2005). For HONO, a rate constant for the reaction with $\mathrm{SF}_{5}^{-}$is not known. However, during simultaneous calibration of $\mathrm{HONO}$ and $\mathrm{HNO}_{3}$ (Jurkat et al., 2011), the calibration factor for a similar setup was found to be of the same magnitude. Collisions of product ions with neutral molecules and other ions in the flow reactor and in the collision dissociation chamber (CDC) can lead to their fragmentation, e.g.,

$\mathrm{HFNO}_{3}^{-} \rightarrow \mathrm{NO}_{3}^{-}+\mathrm{HF}$.

The fragment ions $\mathrm{NO}_{2}^{-}$and $\mathrm{Cl}^{-}$are produced in the same way as the products of Reactions (R3) and (R4). The relative amount of fragmentation mainly depends on the pressure in the flow reactor and the CDC controlling the collision frequency with neutral molecules. The energy available for fragmentation is given by the acceleration of the molecules entering the CDC which depends on the pressure gradient between the flow reactor and CDC. The fragmentation can be further controlled by the acceleration voltages applied between the first pin hole and CDC which are responsible for the resultant energy of the ion-molecule collisions.

Depending on the parameters inside the flow reactor and the concentration, the primary product ions can undergo several secondary reactions which have to be considered when evaluating trace gas concentrations. These reactions can become significant, when the trace gas concentration in the flow reactor is rather high or the reaction time is long. The secondorder reaction of e.g., $\mathrm{HNO}_{3}$ reads

$\mathrm{HFNO}_{3}^{-}+\mathrm{HNO}_{3} \rightarrow \mathrm{HNO}_{3} \mathrm{NO}_{3}^{-}+\mathrm{HF}$.

Similar reactions occur when exchanging $\mathrm{HNO}_{3}$ by $\mathrm{HONO}$ or $\mathrm{HCl}$ and $\mathrm{NO}_{3}^{-}$by $\mathrm{NO}_{2}^{-}$or $\mathrm{Cl}^{-}$, respectively. In contrast to the fragmentation process, the second-order reactions are nonlinearly related to the trace gas concentration. In addition, multiple other reactions between different species may occur, enlarging the complexity of the spectrum. To keep data evaluation simple, secondary products should be avoided by lowering the pressure in the flow reactor or diluting the sample flow. Although the measurement of ambient $\mathrm{SO}_{2}$ is also based on a fluoride transfer, the reaction mechanism is slightly different compared to proton-donating gases. In the reaction

$\mathrm{SO}_{2}+\mathrm{SF}_{5}^{-} \rightarrow \mathrm{FSO}_{2}^{-}+\mathrm{SF}_{4}$,

the $\mathrm{F}^{-}$ion couples to the stronger dipole moment of $\mathrm{SO}_{2}$ compared to $\mathrm{SF}_{4}$. As rate coefficient for this reaction, Lovejoy and Wilson (1998) estimate $k_{\mathrm{SO}_{2}}=$ $0.6 \mathrm{~cm}^{3}$ molecules ${ }^{-1} \mathrm{~s}^{-1}$. As stated in Sect. 4, the rate constant is assumed to be identical for ${ }^{32} \mathrm{SO}_{2}$ and ${ }^{34} \mathrm{SO}_{2}$, allowing a permanent in-flight calibration. Due to the simple structure and the absence of secondary products, Reaction (R7) is used to derive the discrimination constant md (see also Sect. 5) of the mass spectrometer between the masses with $83 \mathrm{~m} / \mathrm{z}$ and $127 \mathrm{~m} / \mathrm{z}$ such that

$\left[\mathrm{SF}_{5}^{-}\right]_{0}=\mathrm{md}^{-1}\left[\mathrm{FSO}_{2}^{-}\right]_{\mathrm{SO}_{2}}+\left[\mathrm{SF}_{5}^{-}\right]_{\mathrm{SO}_{2}}$.

The left side of the equation denotes the number of ions without introduction of $\mathrm{SO}_{2}$, and the right side the number of ions after introduction of $\mathrm{SO}_{2}$. Due to charge conservation, the number of reagent ions without $\mathrm{SO}_{2}$ is expected to be the same as the number of product and reagent ions with $\mathrm{SO}_{2}$. However the mass spectrometer sees only a fraction or multiple of the product ions, which is expressed in the mass discrimination factor $\mathrm{md}$.

\subsection{Mass spectrum}

In contrast to the AIMS-H2O mode, AIMS-TG uses a positive potential on the detectors such that negative ions are detected. Tuning to the lenses is optimized for small masses and reduced fragmentation of the ions. The instrument has two operating modes; the mass spectrum mode scans a range from 10 to $200 \mathrm{amu}$ in steps of $0.3 \mathrm{amu}$. Mass spectra are recorded with a time resolution of $30 \mathrm{~s}$ every $10 \mathrm{~min}$ during flight. Additionally, the instrument operates in a so-called hop mode, in which the ion count rate of each selected mass of interest is sequentially counted for 50 or $100 \mathrm{~ms}$ (user defined) and then integrated for a 1 to $0.5 \mathrm{~Hz}$ time interval. These sequentially counted ions are used to derive the concentrations of the trace gases. A mass spectrum obtained 

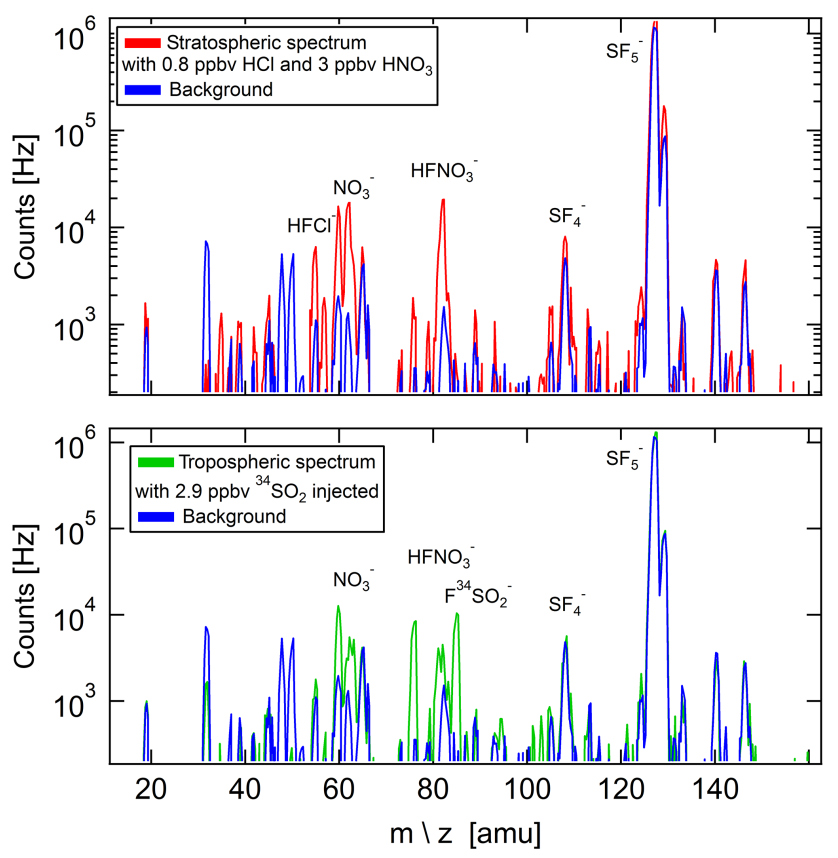

Figure 3. A spectrum of AIMS-TG obtained in stratospheric (upper panel) and tropospheric (lower panel) air south of Cape Verde on 11 September 2012 during TACTS/ESMVal is shown. The $\mathrm{SF}_{5}^{-}$ reagent ion at 127 and $129 \mathrm{amu}$ is most prominent. Nitric acid and hydrochloric acid with their respective ions $\left(\mathrm{HFNO}_{3}^{-}(\mathrm{m} / z\right.$ 82) and $\mathrm{HFCl}^{-}(\mathrm{m} / z 55$ and 57)) are enhanced in the stratosphere (upper panel). The isotopically labeled $\mathrm{SO}_{2}$ is detected as the $\mathrm{F}^{34} \mathrm{SO}_{2}^{-}$ ion $(m / z=85 \mathrm{amu})$ (lower panel). At $m / z 146$ small amounts of $\mathrm{SF}_{6}^{-}$are also present. The stratospheric and tropospheric spectra are compared to a background spectrum taken while synthetic air was introduced in the inlet line.

with AIMS-TG in stratospheric and tropospheric air south of Cape Verde during TACTS/ESMVal is shown in Fig. 3. The most prominent peaks belong to the reagent ion ${ }^{32} \mathrm{SF}_{5}^{-}$ at 127 amu with count rates of several $10^{6}$ counts, and its natural heavier isotope ${ }^{34} \mathrm{SF}_{5}^{-}$at $129 \mathrm{amu}$. The product ions of nitric acid, $\mathrm{HFNO}_{3}^{-}(\mathrm{m} / z=82 \mathrm{amu})$, and hydrochloric acid, $\mathrm{HFCl}^{-},(m / z=55 \mathrm{amu}$ and $57 \mathrm{amu})$ show clear signatures of the stratospheric tracers with the two natural isotopes of the chlorine atom (red line). The calibration of $\mathrm{SO}_{2}$ is done through continuous injection of the ${ }^{34} \mathrm{SO}_{2}$ which is detected as $\mathrm{F}^{34} \mathrm{SO}_{2}^{-}(m / z=85)$. The effect of a low mass resolution results in an artificial increase on the neighboring ions. This effect is largest for the $\mathrm{F}^{32} \mathrm{SO}_{2}^{-}$product $(\mathrm{m} / \mathrm{z}=83 \mathrm{amu})$ ion next to the $\mathrm{HFNO}_{3}^{-}(m / z=82 \mathrm{amu})$ and can be quantified in the lab by an investigation of the background increase at mass 83 by a systematical increase of ion counts on the neighboring mass 82 through addition of $\mathrm{HNO}_{3}$. Generally the resolution is set to allow contamination on the neighboring mass of less than $10 \%$. This is achieved with a full width at half maximum of $1 \mathrm{amu}$ for mass 82 and mass 55, resulting in a low resolving power of $R=m / \Delta m=55$ and 82 , respectively, in line with former quadrupole mass spectrometer measurements (Neuman et al., 2000). The background spectrum is also taken in-flight through injection of synthetic air. A small amount of $\mathrm{SF}_{6}^{-}$is detected at $146 \mathrm{amu} . \mathrm{SF}_{6}^{-}$is also a potential reagent ion used in combination with $\mathrm{HNO}_{3}$ measurements (Huey et al., 1995, 2004). However, due to the large abundance of $\mathrm{SF}_{5}^{-}$of almost 3 orders of magnitude more, it is considered the main reagent ion. The heavier isotope of the reagent ion can be used to monitor the dead time of the detector at high ion numbers of the heavier isotope. Thus if dead time effects are apparent, ${ }^{34} \mathrm{SF}_{5}^{-}$is used to derive the actual reagent ion concentration.

\section{Calibration of AIMS-TG}

The environmental conditions of aircraft measurements are rather extreme for the measurement system regarding temperature, pressure, vibrations and water vapor changes which can hardly be simulated in the laboratory or climate chamber. The change in environmental conditions particularly affects the inlet line and ion spectrum. Therefore it is important to know how ground calibrations transfer to in-flight conditions. We address this issue by calibrating during flight for the specific substances. However, in-flight calibrations are always a trade-off between higher accuracy and the loss of precious airborne measurement time. The methods for in-flight calibration thus have to be fast, they need to be integrated in the airborne instrument setup and they need to produce trace gas concentrations typical for the investigated atmospheric conditions in a stable manner. We use different techniques for the in-flight calibration of the trace gases, adapted to the particular nature of the specific molecule. Next to the general use of in-flight calibrations we comment in Sect. 4.3 and 4.4 on some techniques used exclusively in the laboratory for calibration of $\mathrm{HONO}$ and alternative methods to calibrate $\mathrm{HNO}_{3}$ and $\mathrm{HCl}$.

\subsection{In-flight calibration of $\mathrm{HNO}_{3}$ and $\mathrm{HCl}$}

Commercially available gaseous mixtures of $\mathrm{HNO}_{3}$ and $\mathrm{HCl}$ in nitrogen tend to strongly adsorb at walls of cylinders and flow controllers with stainless steel surfaces. Hence, calibration with gas from a cylinder is critical since extraction from the pressurized containers needs long-term stabilization which is not practical for flight conditions. For the in-flight calibration of AIMS, we use two permeation tubes (VICI Mectronics, USA) filled with an azeotrope solution of $\mathrm{HNO}_{3}$ in water and $\mathrm{HCl}$ in water, respectively. The setup of the permeation devices is shown in Figure 1b. The tubes are partially filled so that a gas volume of a temperature-dependent vapor pressure of the mixture coexists with the liquid phase. The gaseous $\mathrm{HNO}_{3}$ or $\mathrm{HCl}$ can diffuse through a semipermeable membrane made of PFA and is transported to the AIMS instrument by a controlled nitrogen carrier gas flow. Both 

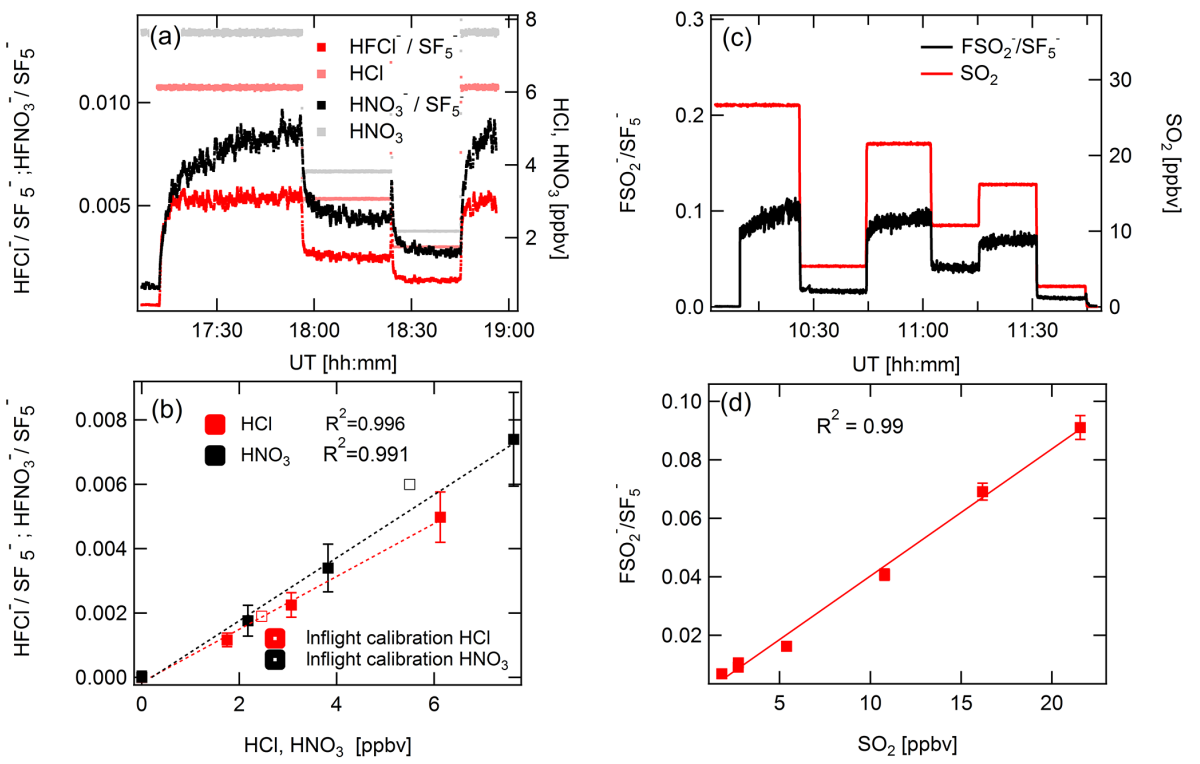

Figure 4. Laboratory calibrations of $\mathrm{HNO}_{3}, \mathrm{HCl}$ and $\mathrm{SO}_{2}$. (a) Time series of product to reagent ion ratios for $\mathrm{HCl}$ (red) and $\mathrm{HNO}$ (black) are shown. While $\mathrm{HCl}$ reaches a plateau within a few minutes, $\mathrm{HNO}_{3}$ needs more time for passivation. Once the sampling line is passivated, the plateau for a given concentration is reached faster for both trace gases (here after 18:45 h). Additionally the concentrations of the added calibration gas are shown in light red and gray. (b) Calibration curves for $\mathrm{HCl}$ (red) and $\mathrm{HNO}_{3}$ (black). The calibration is linear up to high concentrations of $6 \mathrm{ppbv}$ which can occasionally be found in the stratosphere. The error bars denote the precision of a single measurement. For comparison, in-flight calibrations of $\mathrm{HNO}_{3}$ and $\mathrm{HCl}$ are included, represented by the empty square. Panels (c, d) are analogue to (a, b). In contrast to $\mathrm{HCl}$ and $\mathrm{HNO}_{3}, \mathrm{SO}_{2}$ is calibrated for a wider range of concentrations to account for high mixing ratios in volcanic or aircraft plumes.

tubes are housed at constant temperatures and pressures in two separate permeation ovens to guarantee constant permeation rates. The inside of the miniature permeation ovens is either made of a PFA body or a glass tube housed in a heated aluminium block. The oven operates at constant pressure of about 2 bar (above atmospheric pressure) and has a critical orifice made of glass downstream of the permeation oven. Assuming critical conditions, the flow through the orifice is given by the pressure inside the oven. Depending on the diameter of the orifice the flow is between 90 and $110 \mathrm{sccm}$. In combination with a well-defined carrier flow one obtains a calibration gas with a known and constant concentration of the respective trace gas.

The $\mathrm{HNO}_{3}$ tube is a PFA tube filled with a solution of $68 \%$ $\mathrm{HNO}_{3}$ in water. The temperature of the permeation tube is kept constant at 40 or $50^{\circ} \mathrm{C}$, resulting in a permeation rate of $\mathrm{HNO}_{3}$ of $43 \mathrm{ng} \mathrm{min}{ }^{-1}\left(86 \mathrm{ng} \mathrm{min}^{-1}\right.$ ). With these parameters, the concentration of $\mathrm{HNO}_{3}$ in the sample flow is generally $2.9 \mathrm{ppbv}(5.8 \mathrm{ppbv})$. The same concept is used for the calibration of $\mathrm{HCl}$ with a solute concentration of $20 \%$ and the temperature of $55^{\circ} \mathrm{C}$, generating a permeation rate of $18 \mathrm{ng} \mathrm{min}-1$. At 2 bar and with a flow of $90 \mathrm{sccm}$, the $\mathrm{HCl}$ concentration in the sample flow is standardized to $2.6 \mathrm{ppbv}$. Due to the polarity of the molecules, the calibration signal needs a few minutes to stabilize. Therefore during flight, we applied a single point calibration to save measurement time.
Linearity of the calibration is regularly checked between flights and demonstrated in Fig. 4b with a correlation coefficient of $R^{2}=0.991$ for $\mathrm{HNO}_{3}$ and $R^{2}=0.996$ and $\mathrm{HCl}$. The calibration gas flow is generally added to the actual atmospheric sampling flow. Thus, the atmospheric background during calibration should ideally be constant and has to be subtracted from the calibration signal. At the tropopause, the calibration gas concentration is in abundance to the background concentration. In conditions with strong gradients in the concentrations, several calibrations are performed during flight to check consistency. In Fig. 5, two in-flight calibration sequences are shown from the TACTS/ESMVal campaign in 2012 and from the POLSTRACC (POLar STRAtosphere in a changing Climate) campaign which took place in Kiruna in winter 2015/2016. For POLSTRACC, a shorter calibration tube, a valve at the end of the tube and an improved temperature stabilization of the system were deployed to gain a faster response time of the calibration system.

Figure 5a shows an in-flight calibration from TACTS/ESMVal. During the $12 \mathrm{~min}$ calibration sequence, $5.8 \mathrm{ppbv}$ of $\mathrm{HNO}_{3}$ and $2.6 \mathrm{ppbv} \mathrm{HCl}$ were added to the total sample flow. $2.9 \mathrm{ppbv}{ }^{34} \mathrm{SO}_{2}$ was added continuously. The short increase of the $\mathrm{SO}_{2}$ signal after addition of $\mathrm{HNO}_{3}$ is due to flow instabilities. The two reactive gases, $\mathrm{HCl}$ and $\mathrm{HNO}_{3}$, were added successively to investigate the effect of the presence of other trace gases on the ion ratio. A faster 

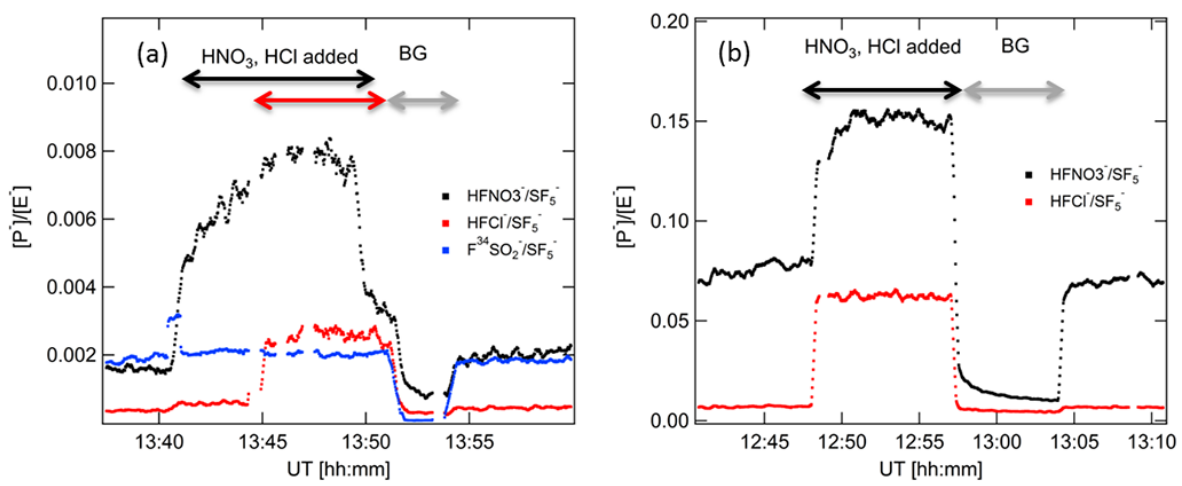

Figure 5. (a) In-flight calibrations of $\mathrm{HCl}, \mathrm{HNO}_{3}$ and $\mathrm{SO}_{2}$ during TACTS/ESMVal. The time series of the ratio of product to reagent ion $\left[P^{-}\right] /\left[E^{-}\right]$for a 12 min calibration sequence is shown. 5.8 ppbv $\mathrm{HNO}_{3}$ was added to the total sample flow for approximately 10 min and stabilized after $4 \mathrm{~min}$. After $3 \mathrm{~min}, 2.6 \mathrm{ppbv} \mathrm{HCl}$ was added for $8 \mathrm{~min}$ and showed a stable signal after $20 \mathrm{~s} .2 .9 \mathrm{ppbv} \mathrm{SO}_{2} \mathrm{was}$ added continuously. A background measurement (BG) was performed shortly after the calibration sequence with $t_{90}$ of $15 \mathrm{~s}$ for $\mathrm{SO}_{2}$ and $\mathrm{HCl}$ and $20 \mathrm{~s}$ for $\mathrm{HNO}_{3}$, respectively. (b) In-flight calibration of $\mathrm{HCl}$ and $\mathrm{HNO}_{3}$ during POLSTRACC. $2.6 \mathrm{ppbv} \mathrm{HCl}$ and $3.5 \mathrm{ppbv} \mathrm{HNO}_{3}$ were added simultaneously for $8 \mathrm{~min}$. $t_{90}$ for the calibration signal is $15 \mathrm{~s}$ for $\mathrm{HCl}$ and $20 \mathrm{~s}$ for $\mathrm{HNO}_{3}$. Background measurements were performed shortly after the calibration with $t_{90}$ of 15-20 s. Improvements of the calibration system between the two campaigns significantly enhance the speed of the calibration measurements. While inlet response times $t_{90}$ for background measurements were the same during the two campaigns, the calibration response time was improved.

stabilization of the signal related to passivation of the walls with polar molecules is observed. After the calibration, a background measurement was performed. $\mathrm{SO}_{2}$ and $\mathrm{HCl}$ reach background levels within $20 \mathrm{~s}, \mathrm{HNO}_{3}$ after $4 \mathrm{~min}$. The in-flight calibration is in the $95 \%$ range of the laboratory calibration fit as shown in Fig. 4b. To assess the response time of the instrument we derive the time until $90 \%$ of the stable signal is reached, hereafter called $t_{90}$. For the optimized calibration system during POLSTRACC, $t_{90}$ for $\mathrm{HNO}_{3}$ was $20 \mathrm{~s}$, for $\mathrm{SO}_{2}$ and $\mathrm{HCl} 15 \mathrm{~s}$, which corresponds to the response time of the inlet. Because of degradation and environmental influences on the permeation tube, the permeation rate changes over time, which becomes significant over timescales of several weeks to months. The calibration of the permeation rate is either done by measuring the weight loss of the permeation tube before and after operation or by introducing the calibration flow through a known amount of water and measuring the ion concentration in the water by means of ion chromatography. The latter technique was applied before and after the TACTS/ESMVal campaign and several times during the CONCERT campaign in 2009. Over a period of approximately 3 months, a reduction of the $\mathrm{HNO}_{3}$ permeation rate of $4 \mathrm{ng} \mathrm{min}{ }^{-1}$ was observed. Within 4 years, we measured a decrease of the permeation rate of approximately a factor of 3 for the $\mathrm{HCl}$ permeation tube. Thus the permeation rate due to aging decreases around $5 \%$ within the period of 3 months. Together with uncertainties arising from flow through the permeation oven, dilution flow and possible losses in the inlet tubing, the overall uncertainty of the $\mathrm{HNO}_{3}$ and $\mathrm{HCl}$ concentrations in the calibration gas is estimated to be $12-16 \%$, which comprises the uncertainty of the ion chromatographic analysis of $7-10 \%$, the error of the mixed gas flows (total sample gas and stability of the permeation oven and line) with an uncertainty of $5-8 \%$. Since the permeation devices need some time (hours to days) to reach equilibrium and thus constant concentrations of the calibrated trace gas, it is remove from the aircraft after each flight and kept at constant temperature and flow with external power in the laboratory. Detection limits, inferred from ground measurements, are between 10 and $15 \mathrm{pptv}$ for a running average of $20 \mathrm{~s}$ and water vapor mixing ratios below 100 ppmv. Compared to Marcy et al. (2005), the detection limit for $\mathrm{HCl}$ is a factor of 2 higher, which may result from different ionization techniques. Response times of former measurements using shorter inlet lines are marginally shorter than for AIMS (Neuman et al., 2001; Zondlo et al., 2003). However, calibration standards are generally added directly to the mass spectrometer instead of the inlet line which enhances the speed for the calibration and background signal but does not capture possible interferences and losses. In-flight calibrations however significantly reduce the uncertainty when compared to uncalibrated measurements (Fiedler et al., 2011). The sensitivity of CIMS techniques differ by an order of magnitude (Neuman et al., 2000; Veres et al., 2008; Roberts et al., 2010; Le Breton et al., 2014). AIMS sensitivities are in the upper range which is mainly a result of high reagent ion count rates and mixing between ion source gas flow and sample flow. Thus, despite the high sensitivities of AIMS, background noise levels still dominate the detection limit. HONO measurements with detection limits of 3 pptv have been reported (Heland et al., 2001) for daytime HONO measurements in unpolluted regions (Zhang et al., 2009). In comparison, the AIMS detection limit for HONO measurements is higher though 
with a better time resolution optimized for measurements in high concentrations on fast-flying jet aircraft.

\subsection{Isotopically labeled $\mathrm{SO}_{2}$}

The use of isotopically labeled calibration gas mixtures is an elegant method that benefits from a different physical behavior of two or more isotopes in the mass spectrometer with the same chemical properties regarding reaction rate constants and surface effects (Roiger et al., 2011). Here we use the heavier isotope ${ }^{34} \mathrm{SO}_{2}$ which undergoes the same chemical reactions in the flow tube and in the inlet as the naturally dominant ${ }^{32} \mathrm{SO}_{2}$ isotope (Speidel et al., 2007). As shown in Fig. 3d the calibration of $\mathrm{SO}_{2}$ is realized by a $150 \mathrm{~mL}$ volume stainless steel cylinder containing $2.7 \mathrm{ppmv}$ of isotopically labeled $\mathrm{SO}_{2}\left({ }^{34} \mathrm{~S} /{ }^{32} \mathrm{~S}=0.96\right)$ in nitrogen. Since the natural isotopic ratio is ${ }^{34} \mathrm{~S} /{ }^{32} \mathrm{~S}=0.0454$ (Lide, 2005), natural $\mathrm{SO}_{2}$ and calibration gas can be detected separately by the mass spectrometer due to a difference in mass of $2 \mathrm{amu}$ of the product ions. The high concentration in the cylinder enables permanent addition of up to $20 \mathrm{sccm}$ of the calibration gas during flight measurements that dilutes the inlet flow by only $0.3 \%$. The price to pay is a $5 \%$ increase in the background signal on the ${ }^{32} \mathrm{SO}_{2}$ mass due to the impurities of the lighter isotope of the calibration gas. However, the benefits dominate since instruments drifts are covered by the permanent calibration and any secondary reactions of the product ions are monitored. During flight, usually a constant amount of $1.5 \mathrm{ppbv}{ }^{34} \mathrm{SO}_{2}$ is added to the sample flow. Adjusting the calibration flow with the MFC (MKS Instruments, Type M100B) further allows checking for linearity of the system regularly which is demonstrated in Fig. 4d. Additionally, in order to check the concentration of the isotopically labeled calibration standard inside the steel cylinder, a second standard with the natural isotopic ratio and a known concentration certified by the manufacturer can simultaneously be introduced into the sample flow. The transmission through pressure reducer and MFC and their passivation is enhanced when allowing a continuous flow through the instruments. The accuracy of $10 \%$ of the isotopic in-flight calibration for $\mathrm{SO}_{2}$ mainly originates from the accuracy of the reference calibration gas, the MFC and possible losses of $\mathrm{SO}_{2}$ in the pressure transducer and other tubing parts. A calibration is shown in Fig. $4 \mathrm{c}$ and $\mathrm{d}$ to demonstrate the linearity of the measurements $\left(R^{2}=0.99\right)$ up to high concentrations which are observed in volcanic or aircraft plumes. The precision of the $\mathrm{SO}_{2}$ measurement is $20 \%$ at the detection limit and $12 \%$ for concentrations higher than $0.5 \mathrm{ppbv}$. The detection limit is at $8 \mathrm{pptv}(1 \sigma)$ for a $20 \mathrm{~s}$ time resolution and water vapor mixing ratios below $100 \mathrm{ppmv}$, which lies in the range of former detection limits for $\mathrm{SO}_{2}$ measurements (Huey et al., 2004; Speidel et al., 2007; Fiedler et al., 2009).

\subsection{Isotopic labeling of $\mathrm{HCl}$ and $\mathrm{HNO}_{3}$}

This section reports on two calibration methods tested in the laboratory. Due to the instability $(\beta)$ of the tested standards for the in-flight measurements, these methods have not been employed on aircraft and will only be briefly reviewed.

The use of isotopically labeled calibration gases of $\mathrm{HNO}_{3}$ and $\mathrm{HCl}$ was tested in the laboratory by means of custommade permeation sources. The heavy isotope of $\mathrm{H}^{15} \mathrm{NO}_{3}$ reacting to mass $\mathrm{HF}^{15} \mathrm{NO}^{3-}(83 \mathrm{amu})$ was used for calibration of $\mathrm{H}^{14} \mathrm{NO}_{3}$ reacting to a lighter product ion of $1 \mathrm{amu}$ less. The heavy isotope solution (Sigma Aldrich) was contained in a custom-made permeation source. The main advantage of the method is the continuous flushing and passivation of the inlet with the heavy isotope of $\mathrm{HNO}_{3}$ which enhances the transmission of the lighter natural isotope. The permeation source generally has less than $5 \%$ contamination from the natural isotope; however, it was unsuitable for the present detection mechanism because mass 83 is similarly occupied by $\mathrm{FSO}_{2}^{-}$, the product ion of $\mathrm{SO}_{2}$. With a generally low $\mathrm{SO}_{2}$ background in the stratosphere, the calibration would have suffered little interference from $\mathrm{SO}_{2}$. It was decided, however, to use a single point calibration with the natural $\mathrm{HNO}_{3}$ isotope in order to be able to detect $\mathrm{SO}_{2}$ on mass 83 .

Isotopic labeling of $\mathrm{HCl}$ is conceptually more difficult than for $\mathrm{HNO}_{3}$. The chlorine atom is naturally abundant with two isotopes ${ }^{35} \mathrm{Cl}$ and ${ }^{37} \mathrm{Cl}$ with a ratio of approximately $3: 1$ and minor contributions from other isotopes. Using $\mathrm{H}^{37} \mathrm{Cl}$ for isotopically labeled calibrations standards, the natural $\mathrm{HCl}$ contribution would impose a large background on the calibration mass $\left(\mathrm{HF}^{37} \mathrm{Cl}^{-}\right.$, see also Sect. 5) and thus enhance the uncertainty of the calibration. Other isotopes are radioactive and therefore unsuitable for aircraft measurements. In addition, a substrate with one single isotope is hard to produce by means of proton enrichment and is therefore costly. As an experimental alternative, a deuterium chloride solution of $35 \%$ deuterium chloride in $\mathrm{D}_{2} \mathrm{O}$ (Sigma Aldrich) was encapsulated into a permeation source. $\mathrm{DCl}$ reacts to neighboring product ions $\left(\mathrm{DF}^{35} \mathrm{Cl}^{-}\right.$and $\mathrm{DF}^{37} \mathrm{Cl}^{-}$; see also Sect. 5) which are $1 \mathrm{amu}$ heavier than the natural isotope. Reaction rates are expected to differ slightly (about $3 \%$ ) but not significantly for this experiment (Atkins and de Paula, 2010). However, reaction with water diffusing through the permeation tube walls and proton transfer in the solution resulted in a fast contamination of the permeation source and generated a large background of $\mathrm{HCl}$ in the mass spectrum. It was therefore unsuitable for in-flight online calibration.

\subsection{Laboratory calibration of HONO}

HONO is photochemically unstable during daylight (Lammel and Cape, 1996) and can therefore not be stored or generated from a permeation source. Due to a larger effort of in situ HONO production, it is calibrated in the laboratory using the reaction of sodium nitrite and water with 
sulfuric acid. The aqueous HONO solution is injected into a temperature-controlled stripping coil with a given vapor pressure. A nitrogen gas flow carries the substances into the mass spectrometer. Generally a second instrument such as the LOPAP (LOng Path Absorption Photometer) instrument (Heland et al., 2001) is used to monitor the resulting HONO mixing ratio during the calibration. During the intercomparison campaign FIONA (Formal Intercomparisons of Observations of Nitrous Acid) (http://euphore.es/fiona/fiona.html) at the EUPHORE photochemistry chamber, AIMS showed a good agreement under various conditions with optical instruments measuring HONO such as DOAS (differential optical absorption spectroscopy) and LOPAP. An example of airborne measurements of HONO is given in Fig. 7 and will be discussed in Sect. 7.

\section{Data evaluation methods}

\subsection{Retrieval of trace gas concentrations for AIMS-TG}

The analytic approach to derive the trace gas concentration for a pseudo-first-order ion-molecule reaction is

$$
\langle\mathrm{TG}\rangle=\frac{l}{k \tau} \frac{1}{\beta \mu} \ln \left(\frac{\left[P^{-}\right]}{\mathrm{md}\left[E^{-}\right]}+1\right),
$$

where $\langle\mathrm{TG}\rangle$ is the trace gas concentration in particles $\mathrm{cm}^{-3}$, $k$ the reaction rate coefficient, $\tau$ is the time available for the reaction, $\beta$ is the dilution factor, $\mu$ the transmission of the inlet lines, md the mass discrimination and $\left[P^{-}\right] /\left[E^{-}\right]$the product to reagent ion ratio. Generally these parameters are not well enough known or are prone to substantial error. Using the approximation $\ln (x+1) \approx x$ for small values of $x$ (equivalent to $\left[P^{-}\right] \ll \operatorname{md}\left[E^{-}\right]$), the trace gas concentration becomes directly proportional to the product to reagent ratio. The systematical error of that approximation is less than $5 \%$ up to a product to reagent ion ratio of 0.1 . This is generally a smaller error than the uncertainties of inlet line transmission or mass discrimination. Gathering all contributions described above in a calibration factor, $\mathrm{CF}$, one obtains the simple equation

$$
\langle\mathrm{TG}\rangle=\mathrm{CF} \frac{\left[P^{-}\right]}{\left[E^{-}\right]} .
$$

With this approximation, CF is the only parameter needed to derive the trace gas concentration and it is characterized by the in-flight calibration. An example of how CF is derived from laboratory calibration sequences for $\mathrm{HNO}_{3}$ and $\mathrm{HCl}$ is shown in Fig. 4a. The linear slope of the ion ratio versus the trace gas concentration is the inverse $\mathrm{CF}$ in $\mathrm{ppbv}^{-1}$. Since the assumption of dry, generally clean air holds true for most upper tropospheric and lower stratospheric conditions, it is the default evaluation approach for AIMS-TG. The CF determined in the laboratory is then compared with the inflight CF. In case of simultaneous measurements of two or more trace gases, determination of the calibration factors is done independently. However, during atmospheric measurements, the $\mathrm{CF}$ is still valid for the derivation of one trace gas concentration. The product masses of $\mathrm{HONO}, \mathrm{SO}_{2}, \mathrm{HCl}$ and $\mathrm{HNO}_{3}$ are in a narrow mass range; thus the same discrimination factor is assumed. In that case, the product ion count rate $\left[P^{-}\right]$in the Reaction (R9) is replaced by the sum off all products $\left(\sum_{j}\left[P_{j}^{-}\right]\right)$. At very high concentrations of one or more trace gases, e.g., in aircraft exhaust or volcanic plumes, the precondition of small product ion count rates might not be fulfilled anytime. Since concentrations of trace gases in the UTLS are generally low, we mainly use Reaction (R10) to derive the concentration.

\section{Data quality and sources of uncertainty}

The data quality depends on various factors like sensitivity of the instrument to a specific trace gas and signal noise. Additionally, any kind of drift affecting count rates, crosssensitivities and uncertainties in the in-flight calibration alter the data quality. These effects will be addressed in the following section.

\subsection{Sensitivity and detection limits}

Instrumental noise is generally determined in the laboratory and compared to in-flight noise levels. The laboratory calibration sequences are the most useful data since they are unaffected by atmospheric variability and usually exhibit periods with stable signals, long enough for sufficient statistics. Instrumental noise is best described by the standard deviation of the signal either for background concentrations or for a known amount of added trace gas. Starting from an idealized statistical approach, the ion count rates can be described by a Poisson distribution. Hence, the standard deviation of the signal equals square root of the count rate. In reality, a couple of factors like variability of the discharge in the ion source, the transmission of the quadrupole or electric noise from the detector increases the signal noise compared to the idealized approach. Particularly ion signals originating from the discharge source enhance the signal and background noise. For the complete AIMS setup, the signal noise is roughly a factor of 2 higher compared to pure statistical noise. However, data quality is not only determined by signal noise but equally by the instrument's sensitivity. At low trace gas concentrations the count rate of the product ion is directly proportional to the trace gas concentration according to Reaction (10). Sticking to this notation, the sensitivity is the reciprocal of the calibration factor, CF. Combining both sensitivity and signal noise, one obtains a useful measure for the data quality at low concentrations, the detection limit. The detection limit is the value below which the signal cannot be distinguished sta- 
Table 1. Typical parameters describing the measurement range and data quality of AIMS-TG. Actual values may differ slightly due to optimization for one specific trace gas. Remarks concern the parameters (time resolution, standard deviation) used to determine the precision and detection limit. The precision is given for $\mathrm{HCl}, \mathrm{SO}_{2}$ and $\mathrm{HNO}_{3}>0.5$ ppbv. The response time $t_{90}$ is the time until $90 \%$ of a stable background or calibration signal is reached.

\begin{tabular}{lrrrrrrr}
\hline $\begin{array}{l}\text { Trace } \\
\text { gas }\end{array}$ & $\begin{array}{r}\text { Sensitivity } \\
\left(\text { counts pptv }^{-1}\right)\end{array}$ & $\begin{array}{r}\text { Detection limit } \\
(\text { pptv) }\end{array}$ & $\begin{array}{r}\text { In-flight detection } \\
\text { limit (pptv) }\end{array}$ & $\begin{array}{r}\text { Accuracy } \\
(\%)\end{array}$ & $\begin{array}{r}\text { Precision } \\
(\%)\end{array}$ & $\begin{array}{r}\text { Remark } \\
(\mathrm{s})\end{array}$ & $t_{90}$ \\
\hline $\mathrm{HNO}_{3}$ & 7.5 & 15 & 20 & 16 & 20 & $20 \mathrm{~s}, 1 \sigma$ & 20 \\
$\mathrm{HCl}$ & 6.5 & 10 & 15 & 12 & 16 & $20 \mathrm{~s}, 1 \sigma$ & 15 \\
$\mathrm{SO}_{2}$ & 8.1 & 8 & 12 & 12 & 12 & $20 \mathrm{~s}, 1 \sigma$ & 15 \\
$\mathrm{HONO}$ & $\sim 7$ & $\sim 40$ & $\sim 40$ & $10-15 \%$ & $\sim 15$ & $1 \mathrm{~s}, 3 \sigma$ & 15 \\
\hline
\end{tabular}

tistically from the background noise. For the trace gas measurements, we use the single standard deviation of the background signal of the ratio $\frac{P^{-}}{E^{-}}$to define the detection limit of a specific trace gas $i$ :

$\mathrm{DL}_{i}=\mathrm{CF}_{i} \cdot \sigma_{i, \text { background }}$

Since the standard deviation of the signal increases with the count rate, the background signal should be kept low to achieve low detection limits. Typical values for sensitivity and detection limit for trace gases routinely measured with AIMS-TG are given in Table 1. For a better comparability to other systems, the sensitivity is given in counts per pptv.

In addition to the noise analysis in the lab, background measurements are frequently performed in-flight on an hourly basis by flushing the inlet line with dry synthetic air in stratospheric regions or scrubbing the air with a nylon filter in more humid regions. Addition of synthetic air is done for $5 \mathrm{~min}$. The nylon filter is optionally available for humid tropospheric conditions; however the techniques suffers from insufficient scrubbing of e.g., $\mathrm{SO}_{2}$. Thus the background drift and detection limit can be monitored and related to lab calibrations regularly. Generally an exponential decrease in the background during the flight was observed if the aircraft was stationed in humid regions where water vapor can accumulate on the inlet walls and then slowly desorbs in dry air. Characteristic timescales of the long-term background decrease of the $\mathrm{HCl}$ and $\mathrm{HNO}_{3}$ signal were between 28 and 50 min (See Fig. S2); thus mainly during accent this effect was observed. A demonstration of a 5 min background measurement sequence in tropospheric air during the flight on 11 September 2012 is given in Fig. 6. Replacing the sample flow with synthetic air for $5 \mathrm{~min}$, background levels are reached after $20 \mathrm{~s}$ for $\mathrm{HCl}$ and $4 \mathrm{~min}$ for $\mathrm{HNO}_{3}$, respectively, with a fast decrease in the first $20 \mathrm{~s}$ of the background measurement to $90 \%$ of the background signal. For nitric acid, this timescale depends sensitively on the atmospheric concentration observed before the background measurement. From these sequences detection limits were inferred that are 5 to $10 \mathrm{pptv}$ higher in-flight than in the laboratory (see Table 1). This is mainly due to the short sequence of the background measurements still influenced by memory effects of

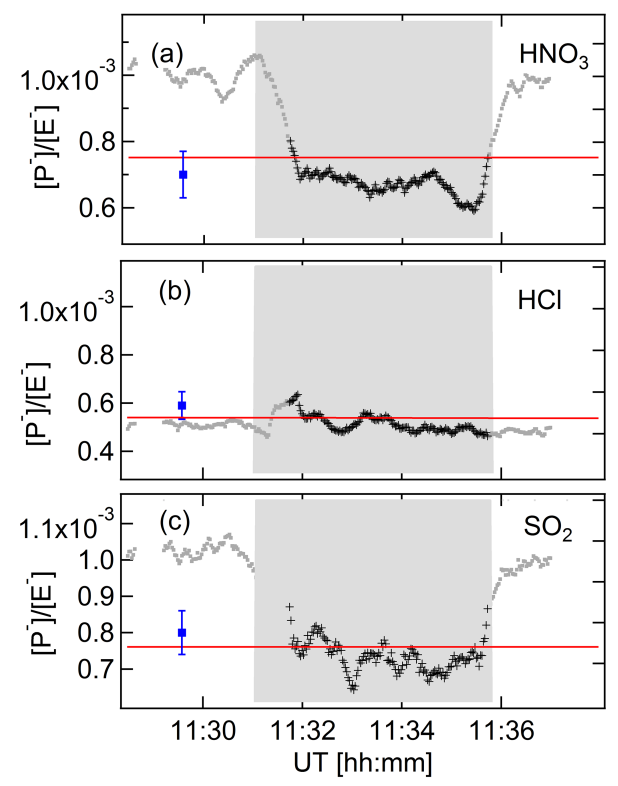

Figure 6. Ion ratios during background measurements for (a) $\mathrm{HNO}_{3}$, (b) $\mathrm{HCl}$ and (c) $\mathrm{SO}_{2}$ in tropospheric air during the flight on 11 September 2012 at 11:31 UT. Gray shaded areas show sequences where synthetic air was introduced. The red curves represent the values applied to correct for the instrumental background during atmospheric measurements. Except for the first hour of the flight, the background can be described by a constant value of $0.75 \times 10^{-3}$ for $\mathrm{HNO}_{3}, 0.54 \times 10^{-3}$ for $\mathrm{HCl}$ and $0.8 \times 10^{-3}$ for $\mathrm{SO}_{2}$. For comparison, the ion ratio averages inferred during laboratory measurements are given (blue squares). Generally, in-flight-based and ground-based measurements agree within the given variability of the laboratory and flight measurements.

the walls. In summary, background values in-flight and on the ground agree within the observed variability.

\subsection{Further instrumental uncertainties}

Despite the uncertainty from calibration procedure, the determination of the background and the approximations in data evaluation, a couple of other factors can lead to an increased uncertainty of the AIMS measurements. 
The vacuum chamber and inlet line can be contaminated with water vapor and other trace gases and aerosol particles. In order to minimize the effect of moisture in the inlet, the whole inlet line is routinely flushed with dry nitrogen during taxi and take-off. Moreover, the absorption and desorption of polar molecules like $\mathrm{HNO}_{3}$ and $\mathrm{HCl}$ from the inlet surface renders the interpretation of the data more difficult. Both gases tend to stick on the wall when prevalent in high concentrations and desorb slowly when concentrations decrease - these are so-called memory effects. In lab measurements, characteristic times to reach equilibration of the inlet line and pressure valve $\left(t_{90}\right)$ are of the order of $500 \mathrm{~s}$ (for 14 ppbv $\mathrm{HNO}_{3}$ ) with significant memory effects. We assign this effect mainly to the passivation of the calibration lines and the reduced flow through the lines. On the ground, calibration set points are run from high concentration to low and back up to high concentrations for verification. During flight, response times of the inlet are significantly reduced due to a higher flow, maintained by the bypass MFC and bypass pump and a lower pressure in the inlet line. Here the $t_{90}$ time is of the order of $20 \mathrm{~s}$ for $\mathrm{HNO}_{3}$ as demonstrated in Fig. $5 \mathrm{~b} . \mathrm{HCl}$ and $\mathrm{SO}_{2}$ are less affected; the characteristic timescales $t_{90}$ are generally shorter around $150 \mathrm{~s}$ for laboratory calibrations (Fig. 4) and about $15 \mathrm{~s}$ for in-flight calibrations (Fig. 5). Although these large gradients in concentrations are rarely met in the UTLS, they may affect measurements in young aircraft or volcanic plumes. Flying through these plumes with strong concentration gradients leads to an underestimation of peak concentrations as well as a broadening of the peak. Therefore, usually an integral of the plume sequence is used. Passivation is achieved by flushing the calibration line on the ground before take-off with $\mathrm{HNO}_{3}$ and $\mathrm{HCl}$, which reduces the response time of the calibration system in-flight.

\subsection{Cross-sensitivity}

The measurement of one specific trace gas can be influenced by other gases. The most prominent candidates for AIMSTG are water vapor and ozone due to their high natural abundance and strong gradients in the UTLS. The sensitivity for $\mathrm{HNO}_{3}$ and $\mathrm{HONO}$ increases with increasing water vapor concentration. For a range from 5 to 150 ppmv typical for the UTLS, this increase is of the order of $10 \%$. At the same time, the background signal also increases by roughly $10 \%$, resulting in a higher detection limit for both trace gases at higher water vapor concentrations. The background resulting from different water vapor concentrations thus has to be precisely known since it is a significant source of error for upper tropospheric conditions with low trace gas concentrations of $\mathrm{HCl}$ and $\mathrm{HNO}_{3}$ and variable water vapor abundance. The change of background due to water vapor is monitored after landing by introducing different concentrations of humidified air to the sampling flow. Calibrating with a dry sample gas would end in a slight overestimation of ambient trace gas concentrations in the upper troposphere. Therefore, the in-flight cali- bration is always pursued in the ambient trace gas conditions. The main reason for the increase in sensitivity is probably the formation of more $\mathrm{SF}_{5}^{-}\left(\mathrm{H}_{2} \mathrm{O}\right)$ clusters with increasing water vapor concentration. These clusters are expected to exhibit a larger cross section for the reaction with ambient trace gases increasing the rate coefficients of Reactions (R2) and (R3). Concerning cross-sensitivities to the background, $m / z 55$ as an example is ambiguously occupied; beside the product ion $\mathrm{HFCl}^{-}, \mathrm{F}\left(\mathrm{H}_{2} \mathrm{O}\right)_{2}^{-}$may form in the presence of water vapor which adds to the background of the $\mathrm{HCl}$ measurements. Similarly, mass $83\left(\mathrm{FSO}_{2}^{-}\right)$is affected by water, presumably due to a second reagent ion production $\left(\mathrm{SCF}^{-}(\mathrm{HF})\right)$. The dependencies on water vapor can be corrected but enhance the uncertainty of the measurement. Thus measurements at water vapor concentrations higher than $100 \mathrm{ppmv}$ are only occasionally evaluated. Cross-sensitivities may influence the measurements at high concentrations of water vapor or other trace gases e.g., in urban pollution plumes. The generally low concentrations in the UTLS, however, do not perturb the AIMS-TG measurements.

\section{Trace gas measurements with AIMS-TG on HALO during TACTS/ESMVal}

The TACTS mission focused on transport mechanisms and the composition of the extratropical tropopause transition layer (ExTL) as well as trace gas distribution in the UTLS. The mission was combined with the ESMVal mission with the same trace gas payload. ESMVal investigated the contribution of different sources like biomass burning, lightning and industrial combustion to the trace gas budget at different altitudes and hemispheres. The data set is used for validation of global chemistry-climate models. Exploiting the HALO potential to fly long distances in various altitudes and over a wide range of latitudes, two flight examples of the ESMVal mission are presented. During the first flight starting in Sal, Cape Verde, and landing in Cape Town, South Africa, different influences from lightning, long-range transport of convective outflow, as well as stratospheric air, was detected. This flight is particularly interesting since all four trace gases showed enhanced mixing ratios at altitudes between 8 and $15 \mathrm{~km}$. The second flight started and landed in Cape Town, aiming to reach the Antarctic polar vortex at latitudes up to $65^{\circ} \mathrm{S}$.

In Fig. 7 a typical flight of the ESMVal mission is presented. HALO was generally flying at altitudes between 11 and $15 \mathrm{~km}$, probing one profile during each transect from 15 down to $4 \mathrm{~km}$. A time series of $\mathrm{HNO}_{3}, \mathrm{HONO}, \mathrm{NO}, \mathrm{NO}_{y}$, $\mathrm{SO}_{2}, \mathrm{HCl}$ and distance to the tropopause from a flight on 11 September 2012 is shown. AIMS data are given for a $20 \mathrm{~s}$ running average. The sum of reactive nitrogen oxides $\left(\mathrm{NO}_{y}=\mathrm{NO}, \mathrm{NO}_{2}, \mathrm{HNO}_{3}, \mathrm{HONO}, \mathrm{PAN}, \ldots\right)$ was measured by AENEAS (Atmospheric nitrogen oxides measuring system). AENEAS is a two-channel chemiluminescence detec- 


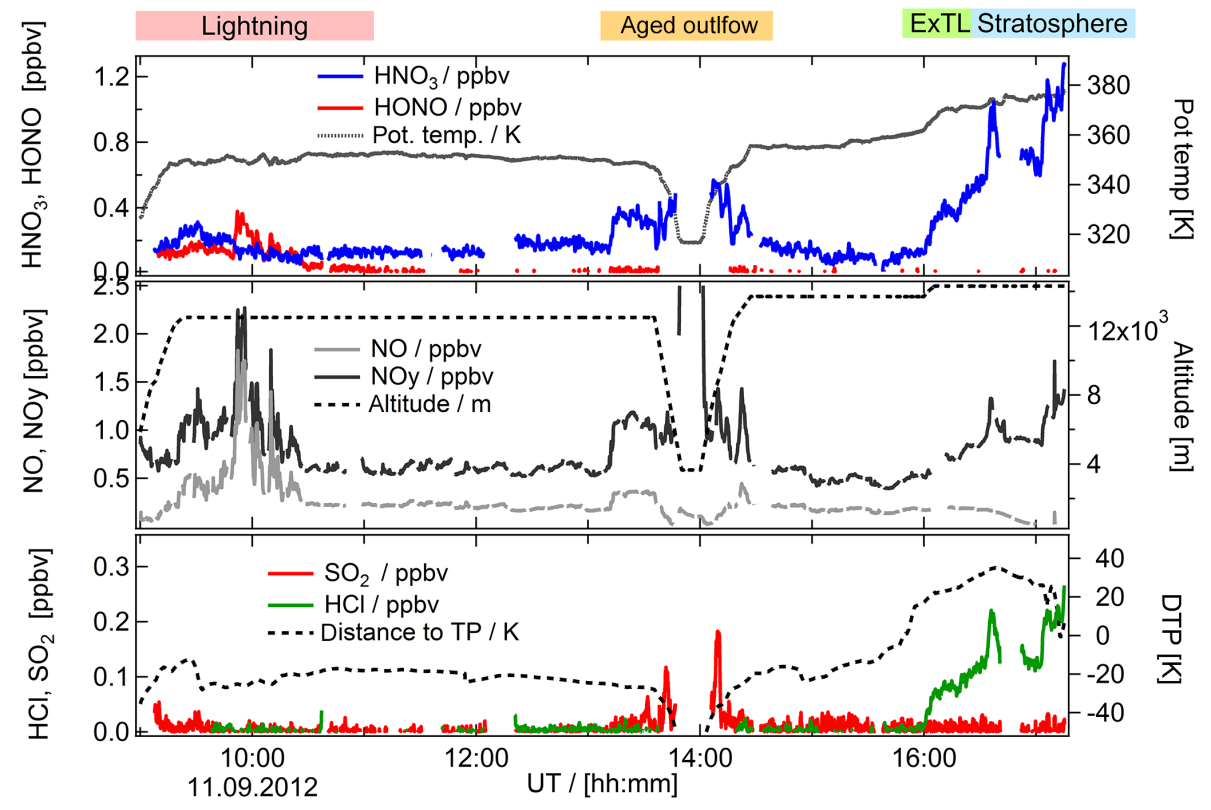

Figure 7. A time series of $\mathrm{HNO}_{3}, \mathrm{HONO}$ and temperature (upper panel), $\mathrm{NO}$ and $\mathrm{NO}_{y}$ and altitude (middle panel) and $\mathrm{SO} 2, \mathrm{HCl}$, distance to the tropopause (lower panel) from the flight on 11 September 2012 during the TACTS/ESMVal mission is shown. The aircraft started in Sal, Cape Verde, and landed in Cape Town, South Africa. Tropospheric tracers, with strong influences from lightning, were measured in the first part of the flight; $\mathrm{HONO}$ signatures are present in a thunderstorm west of Africa simultaneously with $\mathrm{NO}_{y}, \mathrm{NO}$ and $\mathrm{HNO}_{3}$. $\mathrm{HONO}$ mixing ratios of up to $0.38 \mathrm{ppbv}$ coincide with the $\mathrm{NO}$ enhancement, indicating a recent influence of lightning in decaying convective cells. In the second part of the flight, increases in $\mathrm{SO}_{2}$ and $\mathrm{HNO}_{3}$ were measured in aged outflow air at 9 and $11 \mathrm{~km}$, originating potentially from biomass burning in east Africa. The plume was encountered twice during descent and ascent of the profile. In the last part of the flight, HALO reached the stratosphere, indicated by simultaneous increase in $\mathrm{HCl}$ and $\mathrm{HNO}_{3}$ and the distance to the tropopause.

tor in connection with a gold converter, reducing higher oxidation stages to NO (Ziereis et al., 2000). Detection limits are 8 pptv, with an overall accuracy of $8 \%$ at 0.5 ppbv.

In the first part of the flight, HONO measured in a young thunderstorm cloud to the west of Africa is shown together with $\mathrm{NO}_{y}$ and $\mathrm{NO}$ measurements. Due to its short lifetime of about $10 \mathrm{~min}$ at daytime, measurements of HONO in the upper troposphere are very challenging and generally hardly surpass the detection limit (Dix et al., 2009). Only during this first flight segment were significant HONO signatures detected. The strong correlation of HONO to NO suggests a similar production process and location. Decaying convective cells with contributions from lightning were observed in this region. Between 15 and $20 \%$ of the $\mathrm{NO}_{y}$ was found in the form of $\mathrm{HONO}$. The sum of $\mathrm{HONO}, \mathrm{NO}$ and $\mathrm{HNO}_{3}$ can account for the total nitrogen oxide measurements, thus excluding a significant contribution of PAN (peroxyacetyl nitrate) or other $\mathrm{NO}_{y}$ species inside the air mass. The plume was accompanied by an increase in $\mathrm{CO}$ of about $20 \mathrm{ppbv}$ and a decrease in $\mathrm{O}_{3}$ of $10 \mathrm{ppbv}$ (not shown here) which indicates convective transport in the cloud system and/or ozone titration in a high $\mathrm{NO}_{x}$ environment. Assuming a daytime photolysis rate of HONO and a time frame of the convective and lightning event about 20 min before, the initial HONO concentration is expected to be a factor of 7 to 8 higher. Given that $\mathrm{HONO}$ is a significant source of $\mathrm{OH}$ in the troposphere, our observations suggest a large impact of lightning on the oxidation capacity in the upper troposphere in and around young thunderstorms. In the second part of the flight, during a profile west of Angola, enhanced $\mathrm{SO}_{2}$ was encountered during ascent and descent. One plume was crossed at $11 \mathrm{~km}$ with enhanced $\mathrm{HNO}_{3}$, and the second one between 8 to $9.5 \mathrm{~km}$ with a simultaneous increase in $\mathrm{SO}_{2}$ and $\mathrm{HNO}_{3}$. The plume at $8 \mathrm{~km}$ indicates aged air that originates from continental emissions lifted by convection over the Indian continent and transported to higher latitudes by the subtropical jet. This observation is also supported by the tracer-tracer correlation analysis shown in Fig. 8. Tropospheric and stratospheric tracers have been correlated; while $\mathrm{SO}_{2}$ and $\mathrm{NO}$ are mainly tropospheric tracers, $\mathrm{HCl}$ serves as an unambiguous stratospheric tracer in the upper troposphere. In the upper two panels, stratospheric tracers and ratios of stratospheric tracers are correlated; the lower two panels present a tropospheric branch parallel to the $x$ axis and a stratospheric branch parallel to the $y$ axis.

Different air masses influenced by lightning, aged outflow, the ExTL or the stratosphere, respectively, are color-coded. While the lightning and outflow data show no $\mathrm{HCl}$ enhancement, $\mathrm{SO}_{2}$ is clearly enhanced. These air masses originate from tropospheric sources. The $\mathrm{HNO}_{3}$ contribution to the 

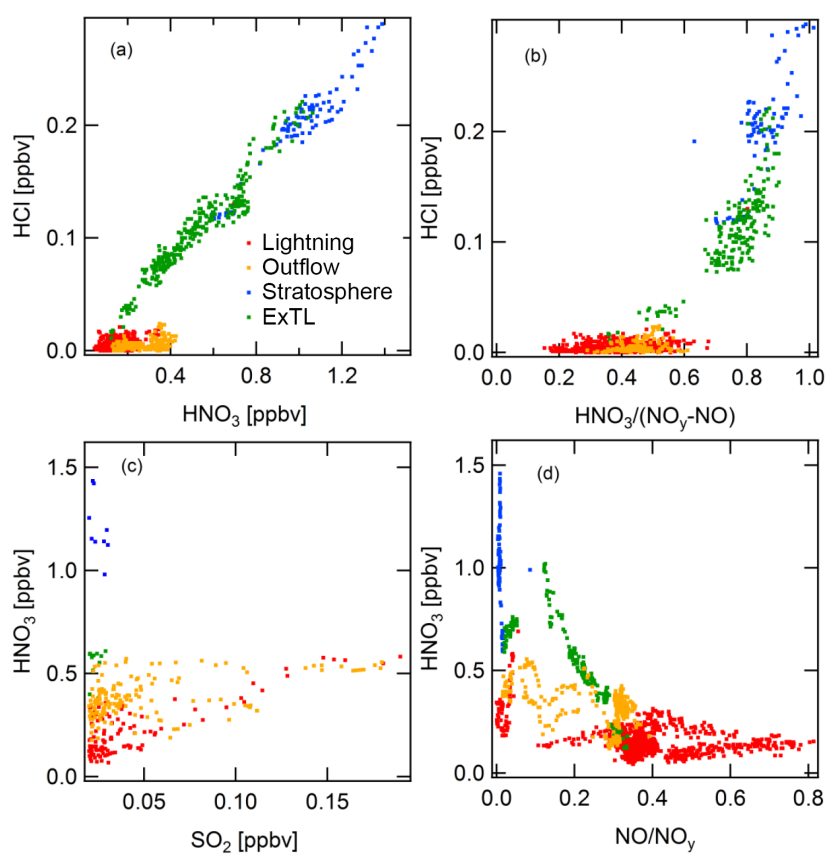

Figure 8. Tracer-tracer correlations of $\mathrm{HCl}, \mathrm{HNO}_{3}, \mathrm{SO}_{2}$ and $\mathrm{NO} / \mathrm{NO}_{y}$ and $\mathrm{HNO}_{3} /\left(\mathrm{NO}_{y}-\mathrm{NO}\right)$ are shown. The correlations are used to differentiate between tropospheric and stratospheric contributions to four different air mass compositions encountered during the flight on 11 September 2012. A lightning-influenced air mass (red), aged outflow (yellow), air from the ExTL (green) and a stratospheric air mass (blue) were encountered. While the red and yellow data show no $\mathrm{HCl}$ enhancement, $\mathrm{SO}_{2}$ and $\mathrm{NO} / \mathrm{NO}_{y}$ are clearly enhanced. $\mathrm{HCl}$ and $\mathrm{HNO}_{3}$ are strongly correlated in the stratosphere. In the region above the tropopause, the ExTL, mixed air was encountered, represented by the decreasing ratio of $\mathrm{HNO}_{3} /\left(\mathrm{NO}_{y}-\mathrm{NO}\right)$ with increasing $\mathrm{HCl}$.

total $\mathrm{NO}_{y}$ budget is higher in the aged outflow, while NO makes up the major part of the lightning-influenced air mass.

At 16:00, HALO crosses the tropopause and enters the ExTL where mixtures of tropospheric and stratospheric air are encountered. The tight correlation of $\mathrm{HCl}$ and $\mathrm{HNO}_{3}$ suggests a major influence of stratospheric air, however with significant contributions from tropospheric tracers like NO. The high correlation coefficient between $\mathrm{HCl}$ and $\mathrm{HNO}_{3}$ of $R^{2}=0.979$ in stratospheric air additionally demonstrates similar response times of the instruments with respect to both substances. Memory effects do not affect the compact correlation of $\mathrm{HNO}_{3}$ with the less reactive gas $\mathrm{HCl}$. The ratio of $\mathrm{NO} / \mathrm{NO}_{y}$ decreases with distance to the tropopause. The ratio of $\mathrm{NO} / \mathrm{NO}_{y}$ also acts as a chemical clock. Nitrogen oxides are injected in the atmosphere as NO that is subsequently converted to other $\mathrm{NO}_{y}$ species e.g., $\mathrm{HNO}_{3}$. Therefore a low $\mathrm{NO} / \mathrm{NO}_{y}$ ratio indicates an aged air mass that is not subject to recent $\mathrm{NO}_{x}$ emissions. In the unperturbed stratosphere, $\mathrm{NO}_{y}$ is dominated by $\mathrm{HNO}_{3}$, indicated by the blue data points. The values near 1 for the $\mathrm{HNO}_{3} /\left(\mathrm{NO}_{y}-\mathrm{NO}\right)$ ratio in the strato-

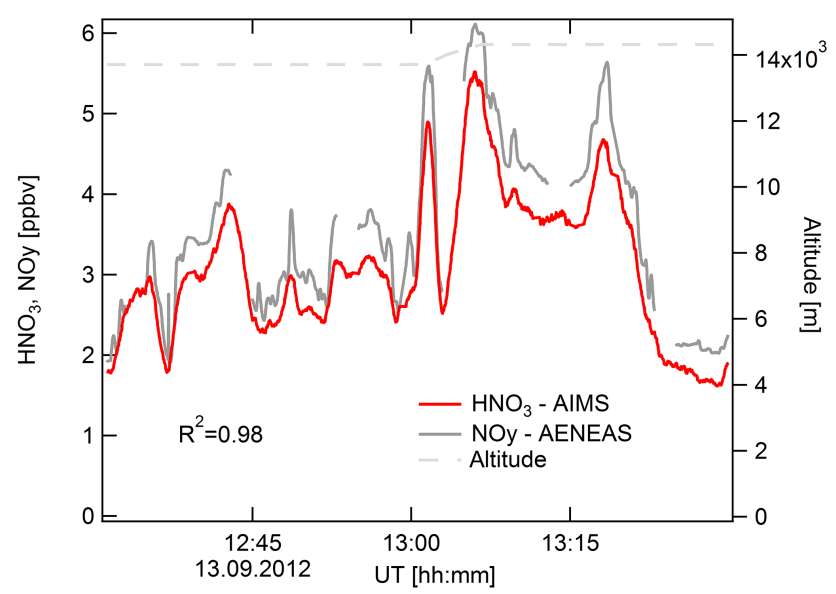

Figure 9. (a) Time series of $\mathrm{HNO}_{3}$, measured by AIMS-TG (red) in the Antarctic stratosphere between 33 and $65^{\circ} \mathrm{S}$ on 13 September 2012, are shown. The dashed line represents the altitude of the aircraft. $\mathrm{HNO}_{3}$ values are highly variable due to mixing at the edge of the polar vortex and reach values of up to $5.2 \mathrm{ppbv}$. For comparison, $\mathrm{NO}_{y}$ measured by AENEAS is shown in gray. The two measurements show good agreement with a correlation coefficient of $R^{2}=0.98$.

sphere are in agreement with Neuman et al. (2001), demonstrating the reliability of the data in stratospheric air. While $\mathrm{HNO}_{3}$ has tropospheric and stratospheric sources, the ratio of $\mathrm{HNO}_{3}$ to $\mathrm{NO}_{y}$ indicates the age of the air mass, similarly to $\mathrm{NO} / \mathrm{NO}_{y}$.

In summary, clear correlations evolve from the combination of different tracers that help to identify the source of enhanced trace gas concentration in the UTLS. Tropospheric and stratospheric air and mixtures appear in defined locations in the tracer-tracer space. Positive slopes of the correlations indicate similar sources, while anti-correlations imply a mixture of reservoirs. The combination of tracers is therefore a suitable tool for air mass characterization from different sources and of different composition and age, and is used here to demonstrate the quality of the measurements from AIMS and AENEAS.

The second measurement example was taken from a flight on 13 September 2012 to the Antarctic polar vortex at latitudes between 33 and $65^{\circ} \mathrm{S}$ (Fig. 9). Considerable changes in $\mathrm{NO}_{y}$ and $\mathrm{HNO}_{3}$ concentration from very low tropospheric values of $0.15 \mathrm{ppbv}$ at $6 \mathrm{~km}$ to high concentration in the lower stratosphere at $14.4 \mathrm{~km}$ with up to $5.2 \mathrm{ppbv}$ were observed by AIMS and AENEAS. Since most of the $\mathrm{NO}_{y}$ is $\mathrm{HNO}_{3}$, both measurements show a good correlation. The difference in the $\mathrm{HNO}_{3}$ and $\mathrm{NO}_{y}$ timeline give an indication that on average 10 to $20 \%$ other reactive nitrogen oxide components such as $\mathrm{ClONO}_{2}$ and $\mathrm{NO}_{x}$ are present. The small-scale filamentary structure suggests recent shear-induced downward transported air from the upper polar vortex. Generally the two instruments agree well with a high correlation coefficient of $R^{2}=0.98$, indicative of a similar response time of the instru- 
ments and adequate accuracy of the in-flight calibration. For this flight and two other flights during the TACTS/ESMVal campaign, AIMS-TG delivered a good validation measurement for $\mathrm{HNO}_{3}$ retrievals of the imaging Fourier transform spectrometer GLORIA (Ungermann et al., 2015). Detailed measurements of $\mathrm{ClONO}_{2}, \mathrm{HCl}$ and $\mathrm{HNO}_{3}$ in the Antarctic polar vortex will be described elsewhere.

\section{Conclusion and outlook}

The AIMS-TG mass spectrometer is a robust measurement system for a variety of trace gas constituents in UTLS region. A custom-made ion source stably generates reagent ions that react selectively with the trace gases to form detectable product ions. Stratospheric tracers like $\mathrm{HCl}$ and $\mathrm{HNO}_{3}$, as well as tropospheric tracers like $\mathrm{HONO}$ and $\mathrm{SO}_{2}$, are sensitive to this reaction and can be detected with high accuracy and spatial resolution. Accuracy is achieved by online and in-flight calibration as well as by the use of non-absorbing PFA in the sampling line. The multitude of trace gases simultaneously detected by AIMS enables the identification of the origin of the air mass, differentiating whether it has a more tropospheric character with e.g., enhanced $\mathrm{SO}_{2}$ or more stratospheric character tagged by the stratospheric tracer $\mathrm{HCl}$.

The instrument has proven its reliability during several airborne campaigns on the research aircraft Falcon and HALO (Voigt et al., 2014; Jurkat et al., 2014). During the first atmospheric HALO mission TACTS/ESMVal in 2012, the instrument was operated with $\mathrm{SF}_{5}^{-}$chemistry to quantify the mixing of the stratospheric tracers $\mathrm{HNO}_{3}$ and $\mathrm{HCl}$ in the UTLS. The in situ measurement of low concentrations of the exclusive stratospheric tracer $\mathrm{HCl}$ is still a unique technique on research aircraft which enables the investigation of different stratosphere-troposphere transport processes. Data quality could be confirmed by comparison with $\mathrm{NO}_{y}$ measurements, which gives a conclusive picture of the $\mathrm{NO}_{y}$ budget in fresh thunderstorms and aged pollution plumes. Furthermore, AIMS measurements served as validation for optical remote sensing instruments (Ungermann et al., 2015).

With the highly flexible airborne mass spectrometer AIMS with two configurations, we developed a multitool to address key issues concerning atmospheric composition of the UTLS and processes related to several trace gases in this region. The instrument is not limited to these two configurations; setups for measurements of various hydrocarbons by proton transfer reactions are under development. Future campaigns with AIMS are planned on HALO to assess the composition of the ExUTLS e.g., during WISE in 2017 (Wave-driven ISentropic Exchange). The Supplement related to this article is available online
at doi:10.5194/amt-9-1907-2016-supplement.
Acknowledgements. The ESMVal aircraft campaign was funded by the DLR-4 Project ESMVal. We thank V. Eyring for leading the overall project, H. Schlager for leading the campaign and all members of the ESMVal team. We thank the German Science Foundation DFG for funding within HALO-SPP 1294. C. Voigt, T. Jurkat and S. Kaufmann are grateful for financing by the Helmholtz Association under contract no. VH-NG-309 and under contract no. W2/W3-60. In addition we thank the flight department of DLR for their great support during the campaign and A. Roiger for an internal review.

The article processing charges for this open-access publication were covered by a Research Centre of the Helmholtz Association.

Edited by: D. Baumgardner

\section{References}

Arnold, F. and Spreng, S.: Balloon-borne mass spectrometer measurements of HCL and HF in the winter Arctic stratosphere, Geophys. Res. Lett., 21, 1255-1258, doi:10.1029/93GL03230, 1994.

Arnold, F., Scheid, J., Stilp, T., Schlager, H., and Reinhardt, M. E.: Measurements of jet aircraft emissions at cruise altitude I: The odd-nitrogen gases $\mathrm{NO}, \mathrm{NO}_{2}, \mathrm{HNO}_{2}$ and $\mathrm{HNO}_{3}$, Geophys. Res. Let., 19, 2421-2424, doi:10.1029/92GL02926, 1992.

Ashfold, M. J., Pyle, J. A., Robinson, A. D., Meneguz, E., Nadzir, M. S. M., Phang, S. M., Samah, A. A., Ong, S., Ung, H. E., Peng, L. K., Yong, S. E., and Harris, N. R. P.: Rapid transport of East Asian pollution to the deep tropics, Atmos. Chem. Phys., 15, 3565-3573, doi:10.5194/acp-15-3565-2015, 2015.

Atkins, P. W. and de Paula, J.: Physical Chemistry, 9th Edn., Oxford University Press. ISBN 978-0-19-954337-3, 1008 pp., 2010.

Berresheim, H., Elste, T., Tremmel, H. G., Allen, A. G., Hansson, H. C., Rosman, K., Dal Maso, M., Mäkelä, J. M., Kulmala, M., and O'Dowd, C. D.: Gas-aerosol relationships of $\mathrm{H}_{2} \mathrm{SO}_{4}$, MSA, and $\mathrm{OH}$ : Observations in the coastal marine boundary layer at Mace Head, Ireland, J. Geophys. Res., 107, 8100, doi:10.1029/2000JD000229, 2002.

Crutzen, P. J. and Arnold, F.: Nitric acid cloud formation in the cold Antarctic stratosphere: a major cause for the springtime "ozone hole", Nature, 324, 651-655, 1986.

Dix, B., Brenninkmeijer, C. A. M., Frieß, U., Wagner, T., and Platt, U.: Airborne multi-axis DOAS measurements of atmospheric trace gases on CARIBIC long-distance flights, Atmos. Meas. Tech., 2, 639-652, doi:10.5194/amt-2-639-2009, 2009.

Fiedler, V., Nau, R., Ludmann, S., Arnold, F., Schlager, H., and Stohl, A.: East Asian $\mathrm{SO}_{2}$ pollution plume over Europe - Part 1: Airborne trace gas measurements and source identification by particle dispersion model simulations, Atmos. Chem. Phys., 9, 4717-4728, doi:10.5194/acp-9-4717-2009, 2009.

Fiedler, V., Arnold, F., Ludmann, S., Minikin, A., Hamburger, T., Pirjola, L., Dörnbrack, A., and Schlager, H.: African biomass burning plumes over the Atlantic: aircraft based measurements and implications for $\mathrm{H}_{2} \mathrm{SO}_{4}$ and $\mathrm{HNO}_{3}$ mediated smoke particle activation, Atmos. Chem. Phys., 11, 3211-3225, doi:10.5194/acp-11-3211-2011, 2011. 
Hanke, M., Umann, B., Uecker, J., Arnold, F., and Bunz, H.: Atmospheric measurements of gas-phase $\mathrm{HNO}_{3}$ and $\mathrm{SO}_{2}$ using chemical ionization mass spectrometry during the MINATROC field campaign 2000 on Monte Cimone, Atmos. Chem. Phys., 3, 417436, doi:10.5194/acp-3-417-2003, 2003.

Hegglin, M. I., Gettelman, A., Hoor, P., Krichevsky, R., Manney, G. L., Pan, L. L., Son, S. W., Stiller, G., Tilmes, S., Walker, K. A., Eyring, V., Shepherd, T. G., Waugh, D., Akiyoshi, H., Añel, J. A., Austin, J., Baumgaertner, A., Bekki, S., Braesicke, P., Brühl, C., Butchart, N., Chipperfield, M., Dameris, M., Dhomse, S., Frith, S., Garny, H., Hardiman, S. C., Jöckel, P., Kinnison, D. E., Lamarque, J. F., Mancini, E., Michou, M., Morgenstern, O., Nakamura, T., Olivié, D., Pawson, S., Pitari, G., Plummer, D. A., Pyle, J. A., Rozanov, E., Scinocca, J. F., Shibata, K., Smale, D., Teyssèdre, H., Tian, W., and Yamashita, Y.: Multimodel assessment of the upper troposphere and lower stratosphere: Extratropics, J. Geophys. Res.-Atmos., 115, D00M09, doi:10.1029/2010JD013884, 2010.

Heland, J., Kleffmann, J., Kurtenbach, R., and Wiesen, P.: A New Instrument To Measure Gaseous Nitrous Acid (HONO) in the Atmosphere, Environ. Sci. Technol., 35, 3207-3212, doi:10.1021/es000303t, 2001.

Holton, J. R., Haynes, P. H., McIntyre, M. E., Douglass, A. R., Rood, R. B., and Pfister, L.: Stratosphere-Troposphere Exchange, Rev. Geophys., 33, 403-439, doi:10.1029/95rg02097, 1995.

Hoor, P., Gurk, C., Brunner, D., Hegglin, M. I., Wernli, H., and Fischer, H.: Seasonality and extent of extratropical TST derived from in-situ CO measurements during SPURT, Atmos. Chem. Phys., 4, 1427-1442, doi:10.5194/acp-4-1427-2004, 2004.

Huey, L. G., Hanson, D. R., and Howard, C. J.: Reactions of $\mathrm{SF}_{6}^{-}$ and $\mathrm{I}^{-}$with Atmospheric Trace Gases, J. Phys. Chem., 99, 50015008, doi:10.1021/j100014a021, 1995.

Huey, L. G., Tanner, D. J., Slusher, D. L., Dibb, J. E., Arimoto, R., Chen, G., Davis, D., Buhr, M. P., Nowak, J. B., Mauldin Iii, R. L., Eisele, F. L., and Kosciuch, E.: CIMS measurements of $\mathrm{HNO}_{3}$ and $\mathrm{SO}_{2}$ at the South Pole during ISCAT 2000, Atmos. Environ., 38, 5411-5421, doi:10.1016/j.atmosenv.2004.04.037, 2004.

Jurkat, T., Voigt, C., Arnold, F., Schlager, H., Aufmhoff, H., Schmale, J., Schneider, J., Lichtenstern, M., and Dörnbrack, A.: Airborne stratospheric ITCIMS measurements of $\mathrm{SO}_{2}, \mathrm{HCl}$, and $\mathrm{HNO}_{3}$ in the aged plume of volcano Kasatochi, J. Geophys. Res.Atmos., 115, D00L17, doi:10.1029/2010JD013890, 2010.

Jurkat, T., Voigt, C., Arnold, F., Schlager, H., Kleffmann, J., Aufmhoff, H., Schauble, D., Schaefer, M., and Schumann, U.: Measurements of $\mathrm{HONO}, \mathrm{NO}, \mathrm{NO}_{y}$ and $\mathrm{SO}_{2}$ in aircraft exhaust plumes at cruise, Geophys. Res. Lett., 38, L10807, doi:10.1029/2011g1046884, 2011.

Jurkat, T., Voigt, C., Kaufmann, S., Zahn, A., Sprenger, M., Hoor, P., Bozem, H., Müller, S., Dörnbrack, A., Schlager, H., Bönisch, H., and Engel, A.: A quantitative analysis of stratospheric $\mathrm{HCl}, \mathrm{HNO}_{3}$, and $\mathrm{O}_{3}$ in the tropopause region near the subtropical jet, Geophys. Res. Lett., 41, 3315-3321, doi:10.1002/2013GL059159, 2014.

Kaufmann, S., Voigt, C., Jeßberger, P., Jurkat, T., Schlager, H., Schwarzenboeck, A., Klingebiel, M., and Thornberry, T.: In situ measurements of ice saturation in young contrails, Geophys. Res. Lett., 41, 702-709, 10.1002/2013GL058276, 2014.

Kaufmann, S., Voigt, C., Jurkat, T., Thornberry, T., Fahey, D. W., Gao, R.-S., Schlage, R., Schäuble, D., and Zöger, M.: The air- borne mass spectrometer AIMS - Part 1: AIMS- $\mathrm{H}_{2} \mathrm{O}$ for UTLS water vapor measurements, Atmos. Meas. Tech., 9, 939-953, doi:10.5194/amt-9-939-2016, 2016.

Kürten, A., Rondo, L., Ehrhart, S., and Curtius, J.: Performance of a corona ion source for measurement of sulfuric acid by chemical ionization mass spectrometry, Atmos. Meas. Tech., 4, 437-443, doi:10.5194/amt-4-437-2011, 2011.

Lacis, A. A., Wuebbles, D. J., and Logan, J. A.: Radiative forcing of climate by changes in the vertical distribution of ozone, J. Geophys. Res.-Atmos., 95, 9971-9981, doi:10.1029/JD095iD07p09971, 1990.

Lammel, G. and Cape, J. N.: Nitrous acid and nitrite in the atmosphere, Chem. Soc. Rev., 25, 361-369, doi:10.1039/CS9962500361, 1996.

Lary, D. J. and Aulov, O.: Space-based measurements of $\mathrm{HCl}$ : Intercomparison and historical context, J. Geophys. Res.-Atmos., 113, D15S04, doi:10.1029/2007JD008715, 2008.

Le Breton, M., Bacak, A., Muller, J. B. A., Xiao, P., Shallcross, B. M. A., Batt, R., Cooke, M. C., Shallcross, D. E., Bauguitte, S. J. B., and Percival, C. J.: Simultaneous airborne nitric acid and formic acid measurements using a chemical ionization mass spectrometer around the UK: Analysis of primary and secondary production pathways, Atmos. Environ., 83, 166-175, doi:10.1016/j.atmosenv.2013.10.008, 2014.

Lovejoy, E. R. and Wilson, R. R.: Kinetic Studies of Negative Ion Reactions in a Quadrupole Ion Trap? Absolute Rate Coefficients and Ion Energies, J. Phys. Chem. A, 102, 2309-2315, doi:10.1021/jp9733911, 1998.

Marcy, T. P., Fahey, D. W., Gao, R. S., Popp, P. J., Richard, E. C., Thompson, T. L., Rosenlof, K. H., Ray, E. A., Salawitch, R. J., Atherton, C. S., Bergmann, D. J., Ridley, B. A., Weinheimer, A. J., Loewenstein, M., Weinstock, E. M., and Mahoney, M. J.: Quantifying Stratospheric Ozone in the Upper Troposphere with in Situ Measurements of HCl, Science, 304, 261265, doi:10.1126/science.1093418, 2004.

Marcy, T. P., Gao, R. S., Northway, M. J., Popp, P. J., Stark, H., and Fahey, D. W.: Using chemical ionization mass spectrometry for detection of $\mathrm{HNO}_{3}, \mathrm{HCl}$, and $\mathrm{ClONO}_{2}$ in the atmosphere, Int. J. Mass Spectrom. 243, 63-70, doi:10.1016/j.ijms.2004.11.012, 2005.

Neuman, J. A., Huey, L. G., Ryerson, T. B., and Fahey, D. W.: Study of Inlet Materials for Sampling Atmospheric Nitric Acid, Environ. Sci. Technol., 33, 1133-1136, doi:10.1021/es980767f, 1999.

Neuman, J. A., Gao, R. S., Schein, M. E., Ciciora, S. J., Holecek, J. C., Thompson, T. L., Winkler, R. H., McLaughlin, R. J., Northway, M. J., Richard, E. C., and Fahey, D. W.: A fast-response chemical ionization mass spectrometer for in situ measurements of $\mathrm{HNO}_{3}$ in the upper troposphere and lower stratosphere, Rev. Sci. Instrum., 71, 3886-3894, doi:10.1063/1.1289679, 2000.

Neuman, J. A., Gao, R. S., Fahey, D. W., Holecek, J. C., Ridley, B. A., Walega, J. G., Grahek, F. E., Richard, E. C., McElroy, C. T., Thompson, T. L., Elkins, J. W., Moore, F. L., and Ray, E. A.: In situ measurements of $\mathrm{HNO}_{3}, \mathrm{NO}_{y}, \mathrm{NO}$, and $\mathrm{O}_{3}$ in the lower stratosphere and upper troposphere, Atmos. Environ., 35, 57895797, doi:10.1016/S1352-2310(01)00354-5, 2001.

Nowak, J. B., Neuman, J. A., Kozai, K., Huey, L. G., Tanner, D. J., Holloway, J. S., Ryerson, T. B., Frost, G. J., McKeen, S. A., and Fehsenfeld, F. C.: A chemical ionization mass spectrometry 
technique for airborne measurements of ammonia, J. Geophys. Res.-Atmos., 112, D10S02, doi:10.1029/2006JD007589, 2007.

Pan, L. L., Randel, W. J., Gary, B. L., Mahoney, M. J., and Hintsa, E. J.: Definitions and sharpness of the extratropical tropopause: A trace gas perspective, J. Geophys. Res., 109, D23103, doi:10.1029/2004JD004982, 2004.

Reiner, T., Möhler, O., and Arnold, F.: Improved atmospheric trace gas measurements with an aircraft-based tandem mass spectrometer: Ion identification by mass-selected fragmentation studies, J. Geophys. Res.-Atmos., 103, 31309-31320, doi:10.1029/1998JD100003, 1998.

Riese, M., Ploeger, F., Rap, A., Vogel, B., Konopka, P., Dameris, M., and Forster, P.: Impact of uncertainties in atmospheric mixing on simulated UTLS composition and related radiative effects, J. Geophys. Res.-Atmos., 117, D16305, doi:10.1029/2012JD017751, 2012.

Roberts, J. M., Veres, P., Warneke, C., Neuman, J. A., Washenfelder, R. A., Brown, S. S., Baasandorj, M., Burkholder, J. B., Burling, I. R., Johnson, T. J., Yokelson, R. J., and de Gouw, J.: Measurement of HONO, HNCO, and other inorganic acids by negative-ion proton-transfer chemical-ionization mass spectrometry (NI-PT-CIMS): application to biomass burning emissions, Atmos. Meas. Tech., 3, 981-990, doi:10.5194/amt-3-981-2010, 2010.

Roiger, A., Aufmhoff, H., Stock, P., Arnold, F., and Schlager, H.: An aircraft-borne chemical ionization -ion trap mass spectrometer (CI-ITMS) for fast PAN and PPN measurements, Atmos. Meas. Tech., 4, 173-188, doi:10.5194/amt-4-173-2011, 2011.

Schlager, H. and Arnold, F.: Measurements of stratospheric gaseous nitric acid in the winter Arctic vortex using a novel rocket-borne mass spectrometric method, Geophys. Res. Lett., 17, 433-436, doi:10.1029/GL017i004p00433, 1990.

Schneider, J., Arnold, F., Bürger, V., Droste-Franke, B., Grimm, F., Kirchner, G., Klemm, M., Stilp, T., Wohlfrom, K. H., Siegmund, P., and van Velthoven, P. F. J.: Nitric acid $\left(\mathrm{HNO}_{3}\right)$ in the upper troposphere and lower stratosphere at midlatitudes: New results from aircraft-based mass spectrometric measurements, J. Geophys. Res., 103, 25337-25343, doi:10.1029/98JD02240, 1998.

Schumann, U. and Huntrieser, H.: The global lightning-induced nitrogen oxides source, Atmos. Chem. Phys., 7, 3823-3907, doi:10.5194/acp-7-3823-2007, 2007.

Seinfeld, J. H. and Pandis, S. N.: Atmospheric Chemistry and Physics, 1st Edn., Wiley, New York, USA, 164-224, 1998.

Speidel, M., Nau, R., Arnold, F., Schlager, H., and Stohl, A.: Sulfur dioxide measurements in the lower, middle and upper troposphere: Deployment of an aircraft-based chemical ionization mass spectrometer with permanent in-flight calibration, Atmos. Environ., 41, 2427-2437, doi:10.1016/j.atmosenv.2006.07.047, 2007.

Ungermann, J., Pan, L. L., Kalicinsky, C., Olschewski, F., Knieling, P., Blank, J., Weigel, K., Guggenmoser, T., Stroh, F., Hoffmann, L., and Riese, M.: Filamentary structure in chemical tracer distributions near the subtropical jet following a wave breaking event, Atmos. Chem. Phys., 13, 10517-10534, doi:10.5194/acp13-10517-2013, 2013.
Ungermann, J., Blank, J., Dick, M., Ebersoldt, A., Friedl-Vallon, F., Giez, A., Guggenmoser, T., Höpfner, M., Jurkat, T., Kaufmann, M., Kaufmann, S., Kleinert, A., Krämer, M., Latzko, T., Oelhaf, H., Olchewski, F., Preusse, P., Rolf, C., Schillings, J., Suminska-Ebersoldt, O., Tan, V., Thomas, N., Voigt, C., Zahn, A., Zöger, M., and Riese, M.: Level 2 processing for the imaging Fourier transform spectrometer GLORIA: derivation and validation of temperature and trace gas volume mixing ratios from calibrated dynamics mode spectra, Atmos. Meas. Tech., 8, 24732489, doi:10.5194/amt-8-2473-2015, 2015.

Veres, P., Roberts, J. M., Warneke, C., Welsh-Bon, D., Zahniser, M., Herndon, S., Fall, R., and de Gouw, J.: Development of negative-ion proton-transfer chemical-ionization mass spectrometry (NI-PT-CIMS) for the measurement of gas-phase organic acids in the atmosphere, Int. J. Mass Spectrom., 274, 48-55, doi:10.1016/j.ijms.2008.04.032, 2008.

Viggiano, A. A. and Hunton, D. E.: Airborne mass spectrometers: four decades of atmospheric and space research at the Air Force Research Laboratory, J. Mass Spectrom., 34, 1107-1129, 1999.

Voigt, C., Schreiner, J., Kohlmann, A., Zink, P., Mauersberger, K., Larsen, N., Deshler, T., Kroger, C., Rosen, J., Adriani, A., Cairo, F., Di Donfrancesco, G., Viterbini, M., Ovarlez, J., Ovarlez, H., David, C., and Dornbrack, A.: Nitric Acid Trihydrate (NAT) in Polar Stratospheric Clouds, Science, 290, 1756-1758, doi:10.1126/science.290.5497.1756, 2000.

Voigt, C., Schumann, U., Jurkat, T., Schäuble, D., Schlager, H., Petzold, A., Gayet, J.-F., Krämer, M., Schneider, J., Borrmann, S., Schmale, J., Jessberger, P., Hamburger, T., Lichtenstern, M., Scheibe, M., Gourbeyre, C., Meyer, J., Kübbeler, M., Frey, W., Kalesse, H., Butler, T., Lawrence, M. G., Holzäpfel, F., Arnold, F., Wendisch, M., Döpelheuer, A., Gottschaldt, K., Baumann, R., Zöger, M., Sölch, I., Rautenhaus, M., and Dörnbrack, A.: In-situ observations of young contrails - overview and selected results from the CONCERT campaign, Atmos. Chem. Phys., 10, 90399056, doi:10.5194/acp-10-9039-2010, 2010.

Voigt, C., Jessberger, P., Jurkat, T., Kaufmann, S., Baumann, R., Schlager, H., Bobrowski, N., Giuffrida, G., and Salerno, G.: Evolution of $\mathrm{CO}_{2}, \mathrm{SO}_{2}, \mathrm{HCl}$, and $\mathrm{HNO}_{3}$ in the volcanic plumes from Etna, Geophys. Res. Lett., 41, 2196-2203, doi:10.1002/2013GL058974, 2014.

Voigt, C., Minikin, A., and Schumann, U.: The airborne experiment on natural cirrus and contrail-cirrus with the new High Altitude LOng range research aircraft HALO, B. Am. Meteorol. Soc., in review, 2016.

Zhang, N., Zhou, X., Shepson, P. B., Gao, H., Alaghmand, M., and Stirm, B.: Aircraft measurement of HONO vertical profiles over a forested region, Geophys. Res. Lett., 36, L15820, doi:10.1029/2009GL038999, 2009.

Zondlo, M. A., Mauldin, R. L., Kosciuch, E., Cantrell, C. A., and Eisele, F. L.: Development and characterization of an airbornebased instrument used to measure nitric acid during the NASA Transport and Chemical Evolution over the Pacific field experiment, J. Geophys. Res., 108, 8793, doi:10.1029/2002JD003234, 2003. 